\title{
Primary versus secondary contributions to particle number concentrations in the European boundary layer
}

\author{
C. L. Reddington ${ }^{1}$, K. S. Carslaw ${ }^{1}$, D. V. Spracklen ${ }^{1}$, M. G. Frontoso ${ }^{2}$, L. Collins ${ }^{1}$, J. Merikanto ${ }^{1,3}$, A. Minikin ${ }^{4}$, \\ T. Hamburger ${ }^{4}$, H. Coe ${ }^{5}$, M. Kulmala ${ }^{3}$, P. Aalto ${ }^{3}$, H. Flentje $^{6}$, C. Plass-Dülmer ${ }^{6}$, W. Birmili ${ }^{7}$, A. Wiedensohler ${ }^{7}$, \\ B. Wehner ${ }^{7}$, T. Tuch ${ }^{7}$, A. Sonntag ${ }^{7}$, C. D. O'Dowd ${ }^{8}$, S. G. Jennings ${ }^{8}$, R. Dupuy ${ }^{8}$, U. Baltensperger ${ }^{9}$, E. Weingartner ${ }^{9}$, \\ H.-C. Hansson ${ }^{10}$, P. Tunved ${ }^{10}$, P. Laj ${ }^{11}$, K. Sellegri ${ }^{12}$, J. Boulon ${ }^{12}$, J.-P. Putaud ${ }^{13}$, C. Gruening $^{13}$, E. Swietlicki ${ }^{14}$, \\ P. Roldin ${ }^{14}$, J. S. Henzing ${ }^{15}$, M. Moerman ${ }^{15}$, N. Mihalopoulos ${ }^{16}$, G. Kouvarakis $^{16}$, V. Ždímal ${ }^{17}$, N. Zíková ${ }^{17}$, \\ A. Marinoni ${ }^{18}$, P. Bonasoni ${ }^{18}$, and R. Duchi ${ }^{18}$ \\ ${ }^{1}$ Institute for Climate and Atmospheric Science, School of Earth and Environment, University of Leeds, Leeds, UK \\ ${ }^{2} \mathrm{C} 2 \mathrm{SM}$ - ETH Zürich, Zürich, Switzerland \\ ${ }^{3}$ Division of Atmospheric Sciences, Department of Physics, University of Helsinki, Helsinki, Finland \\ ${ }^{4}$ Deutsches Zentrum für Luft- und Raumfahrt (DLR), Institut für Physik der Atmosphäre, Oberpfaffenhofen, Germany \\ ${ }^{5}$ School of Earth, Atmospheric and Environmental Sciences, University of Manchester, Manchester, UK \\ ${ }^{6}$ Deutscher Wetterdienst, Meteorologisches Observatorium Hohenpeißenberg, Germany \\ ${ }^{7}$ Leibniz Institute for Tropospheric Research, Leipzig, Germany \\ ${ }^{8}$ School of Physics \& Centre for Climate and Air Pollution Studies, Ryan Institute, National University of Ireland Galway, \\ University Road, Galway, Ireland \\ ${ }^{9}$ Paul Scherrer Institut, Laboratory of Atmospheric Chemistry, 5232 Villigen, Switzerland \\ ${ }^{10}$ Institute for Applied Environmental Research, Stockholm University, Stockholm, Sweden \\ ${ }^{11}$ UJF-Grenoble 1/CNRS, LGGE UMR5183, Grenoble 38041, France \\ ${ }^{12}$ Laboratoire de Météorologie Physique, CNRS, Université Blaise Pascal, Aubière cedex, France \\ ${ }^{13}$ European Commission, Joint Research Centre, Institute of Environment and Sustainability, Ispra, Italy \\ ${ }^{14}$ Division of Nuclear Physics, Lund University, P.O. Box 118, 22100 Lund, Sweden \\ ${ }^{15}$ Netherlands Organisation for Applied Scientific Research TNO, Utrecht, The Netherlands \\ ${ }^{16}$ Environmental Chemical Processes Laboratory, Department of Chemistry, University of Crete, Heraklion, Crete, Greece \\ ${ }^{17}$ Institute of Chemical Process Fundamentals of the AS CR, Prague, Czech Republic \\ ${ }^{18} \mathrm{CNR}$-Institute for Atmospheric Sciences and Climate, Bologna, Italy
}

Received: 31 May 2011 - Published in Atmos. Chem. Phys. Discuss.: 28 June 2011

Revised: 11 November 2011 - Accepted: 16 November 2011 - Published: 5 December 2011

\begin{abstract}
It is important to understand the relative contribution of primary and secondary particles to regional and global aerosol so that models can attribute aerosol radiative forcing to different sources. In large-scale models, there is considerable uncertainty associated with treatments of particle formation (nucleation) in the boundary layer (BL) and in the size distribution of emitted primary particles, leading to uncertainties in predicted cloud condensation nuclei
\end{abstract}

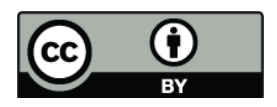

Correspondence to: C. L. Reddington (c.reddington@see.leeds.ac.uk)
(CCN) concentrations. Here we quantify how primary particle emissions and secondary particle formation influence size-resolved particle number concentrations in the BL using a global aerosol microphysics model and aircraft and ground site observations made during the May 2008 campaign of the European Integrated Project on Aerosol Cloud Climate Air Quality Interactions (EUCAARI). We tested four different parameterisations for BL nucleation and two assumptions for the emission size distribution of anthropogenic and wildfire carbonaceous particles. When we emit carbonaceous particles at small sizes (as recommended by the Aerosol Intercomparison project, AEROCOM), the spatial distributions of

Published by Copernicus Publications on behalf of the European Geosciences Union. 
campaign-mean number concentrations of particles with diameter $>50 \mathrm{~nm}\left(N_{50}\right)$ and $>100 \mathrm{~nm}\left(N_{100}\right)$ were well captured by the model $\left(R^{2} \geq 0.8\right)$ and the normalised mean bias (NMB) was also small ( $-18 \%$ for $N_{50}$ and $-1 \%$ for $N_{100}$ ). Emission of carbonaceous particles at larger sizes, which we consider to be more realistic for low spatial resolution global models, results in equally good correlation but larger bias $\left(R^{2} \geq 0.8, \mathrm{NMB}=-52 \%\right.$ and $\left.-29 \%\right)$, which could be partly but not entirely compensated by BL nucleation. Within the uncertainty of the observations and accounting for the uncertainty in the size of emitted primary particles, BL nucleation makes a statistically significant contribution to $\mathrm{CCN}$-sized particles at less than a quarter of the ground sites. Our results show that a major source of uncertainty in $\mathrm{CCN}$-sized particles in polluted European air is the emitted size of primary carbonaceous particles. New information is required not just from direct observations, but also to determine the "effective emission size" and composition of primary particles appropriate for different resolution models.

\section{Introduction}

Atmospheric aerosol particles are generally classified as either primary or secondary depending on their source or origin. Increases in the number concentrations of primary and secondary aerosol from anthropogenic sources have been shown to increase the number concentrations of cloud condensation nuclei $(\mathrm{CCN})$ and cloud drops (e.g. Ramanathan et al., 2001), potentially modifying the properties of clouds (e.g. Lohmann and Feichter, 2005). However, there are large uncertainties associated with the primary emission fluxes and secondary formation rates of atmospheric aerosol, leading to uncertainties in predicted global CCN concentrations (Pierce and Adams, 2009; Merikanto et al., 2009) and ultimately cloud radiative forcing.

Primary particles are emitted directly into the atmosphere from natural sources such as volcanoes, forest fires, sea spray, and windborne dust, and anthropogenic sources such as fossil fuel burning in combustion engines and power plants. Primary particle emissions are estimated to contribute about $55 \%$ of global CCN number concentrations at $0.2 \%$ supersaturation $(\mathrm{CCN}(0.2 \%))$ in the boundary layer $(\mathrm{BL})$, and up to $70 \%$ in polluted continental regions (Merikanto et al., 2009). However, Merikanto et al. (2009) also showed that the estimated contribution of primary particles to $\mathrm{CCN}$ is uncertain due to uncertainties in the size distribution of the emitted particles. Aerosol modelling studies often use different parameterisations for the prescribed emission size distribution (e.g. Textor et al., 2006), leading to significant differences in modelled primary particle number and thus estimated CCN number concentrations (Spracklen et al., 2010). Spracklen et al. (2011) demonstrate that primary carbonaceous particles make an important contribution to the aerosol indirect effect, but estimates vary by a factor of $\sim 3$ depending on the prescribed emission size distribution.

Secondary aerosol particles are formed in the atmosphere through homogeneous nucleation (gas-to-particle conversion) of both natural and anthropogenic gaseous precursors. Once formed, a fraction of nucleated particles undergo subsequent growth through condensation of gas-phase species and self-coagulation, and have the potential to reach particle sizes relevant for $\mathrm{CCN}$ and cloud drop formation (Kerminen et al., 2005). Secondary aerosol formation has been observed to occur globally over many different regions both within the BL and in the upper free troposphere (FT) (see Kulmala et al., 2004, and references therein). Observations (Lihavainen et al., 2003; Laaksonen et al., 2005) and modelling studies (Spracklen et al., 2008; Merikanto et al., 2009; Wang and Penner, 2009; Yu and Luo, 2009) have shown that secondary particles make important contributions to regional and global CCN concentrations. Globally, $45 \%$ of $\mathrm{CCN}(0.2 \%)$ in the $\mathrm{BL}$ are estimated to derive from nucleation (Merikanto et al., 2009), although again this number is uncertain (range 31-49\%) due to uncertainties in nucleation rates and the properties of the primary particles. The uncertainties estimated in Merikanto et al. (2009) may be too low since they did not take into account the multiple plausible nucleation mechanisms (e.g. Spracklen et al., 2010; Metzger et al., 2010; Paasonen et al., 2010; Yu et al., 2010).

The process of binary homogeneous nucleation (BHN) of water and sulphuric acid (Kulmala and Laaksonen, 1990; Kulmala et al., 1998; Vehkamäki et al., 2002), with its strong temperature dependence, is able to reproduce high particle concentrations observed in the cold free and upper troposphere (Adams and Seinfeld, 2002; Spracklen et al., 2005a). But in the warmer lower troposphere, production rates are low (Lucas and Akimoto, 2006). Additional mechanisms have been suggested to explain observed particle formation such as ternary nucleation of water, sulphuric acid and ammonia (Kulmala et al., 2000; Anttila et al., 2005; Merikanto et al., 2007); multi-component nucleation with the participation of organics instead of ammonia (e.g. Metzger et al., 2010); and ion-induced nucleation (Laakso et al., 2002; Modgil et al., 2005). However, with the exception of organics, their contribution to secondary particle concentrations in the continental BL is thought to be fairly limited (Anttila et al., 2005; Laakso et al., 2007; Kulmala et al., 2007; Boy et al., 2008; Elleman and Covert, 2009).

Observations of BL nucleation events at various European surface measurement sites have revealed a strong correlation between the measured particle formation rate and the gasphase concentration of sulphuric acid to the power of one or two (e.g. Sihto et al., 2006; Riipinen et al., 2007; Paasonen et al., 2009, 2010). By measuring newly formed particles $(\sim 1.5 \mathrm{~nm}$ in diameter) in the laboratory, Sipilä et al. (2010) have recently confirmed the linear and squared relationships between nucleation rate and sulphuric acid concentration that are observed in the atmosphere. These 
observations have been used to develop empirical nucleation rates, where the formation rate of sub- $3 \mathrm{~nm}$ molecular clusters $\left(J_{\text {nuc }}\right)$ is related to the gas-phase sulphuric acid concentration $\left(\left[\mathrm{H}_{2} \mathrm{SO}_{4}\right]\right)$ with either a linear i.e. $J_{\text {nuc }}=A\left[\mathrm{H}_{2} \mathrm{SO}_{4}\right]$, or a squared i.e. $J_{\text {nuc }}=K\left[\mathrm{H}_{2} \mathrm{SO}_{4}\right]^{2}$ dependence (e.g. Weber et al., 1996; Kulmala et al., 2006; Sihto et al., 2006; Riipinen et al., 2007).

To describe the observed linear dependence, Kulmala et al. (2006) propose an activation mechanism, where neutral or ion clusters containing one sulphuric acid molecule are activated for further growth. McMurry and Friedlander (1979) explain the squared dependence by proposing a kinetic nucleation mechanism. The values of the nucleation rate coefficients $A$ and $K$; derived from surface observations of particle formation events, vary spatially and temporally in the European BL (e.g. Sihto et al., 2006; Riipinen et al., 2007). Riipinen et al. (2007) find that rate coefficients differ by $\sim 4$ 5 orders of magnitude between different European measurement sites: $A=3.3 \times 10^{-8}-3.5 \times 10^{-4} \mathrm{~s}^{-1}$ (for the activation mechanism) and $K=2.4 \times 10^{-15}-1.3 \times 10^{-10} \mathrm{~cm}^{3} \mathrm{~s}^{-1}$ (for the kinetic mechanism). A model analysis of global particle number concentrations using such empirical relations (Spracklen et al., 2010) shows reasonable agreement with observations at many worldwide sites, albeit with unexplained biases at some sites.

Other condensable vapours such as organic compounds may also influence the nucleation rate (e.g. Metzger et al., 2010; Paasonen et al., 2010; Kerminen et al., 2010). Paasonen et al. (2010) present several nucleation mechanisms that are analogous to the kinetic- and activation-type nucleation theories, but consider the participation of lowvolatility organic compounds in the cluster formation process both in addition to sulphuric acid and as the exclusive nucleating vapour. When evaluated against measurements from European ground sites, Paasonen et al. (2010) find the most promising mechanism involves homogeneous (kinetictype) nucleation of sulphuric acid both homomolecularly and heteromolecularly with the low-volatility organic vapours $\left(J_{\text {nuc }}=k_{1}\left[\mathrm{H}_{2} \mathrm{SO}_{4}\right]^{2}+k_{2}\left[\mathrm{H}_{2} \mathrm{SO}_{4}\right][\right.$ organic $\left.]\right)$. In a laboratory study, Metzger et al. (2010) find measured particle formation rates are proportional to the product concentrations of $\mathrm{H}_{2} \mathrm{SO}_{4}$ and a molecule of an organic condensable species $\left(J_{\text {nuc }}=k\left[\mathrm{H}_{2} \mathrm{SO}_{4}\right][\right.$ organic $\left.]\right)$. Parameterising this process in a global aerosol model showed improved agreement with ambient observations compared to control runs (Metzger et al., 2010).

In this study, we use the same aerosol microphysical model as Spracklen et al. (2010) and extensive observations of European aerosol to perform a more in depth study of primary and secondary aerosol focussing on the European BL. We aim to better understand the absolute and relative contributions of primary and secondary particles to particle concentrations over Europe, and how the contributions vary across the particle size distribution (nucleation, Aitken and accumulation mode sizes). We test different parameterisa- tions for BL nucleation (including the recently proposed organic/sulphuric acid nucleation mechanisms in addition to the widely used activation and kinetic nucleation mechanisms), and different assumptions about the sizes and number concentrations of primary particle emissions that are typical for global aerosol and climate models. To evaluate the model, we use surface-based and airborne measurements of total particle number concentrations and size distribution from the Intensive Observation Period (conducted in May 2008) of the European Integrated Project on Aerosol Cloud Climate Air Quality Interactions (EUCAARI; Kulmala et al., 2009). This study is a demanding test for a relatively low spatial resolution global model against intensive observations in a particular meteorological setting - in this case a highly polluted anti-cyclonic period with a transition to a more dynamic situation.

\section{The EUCAARI intensive observation period}

\subsection{Aircraft and surface-based observations}

A key phase of the EUCAARI Intensive Observation Period (IOP) was the Long Range Experiment (LONGREX), during which in-situ and remote sensing aerosol measurements were performed by the DLR Falcon 20 research aircraft, operating between 6 and 24 May 2008. Particle number concentrations with diameter $\left(D_{\mathrm{p}}\right)>4 \mathrm{~nm}\left(N_{4}\right)$ and $>10 \mathrm{~nm}$ $\left(N_{10}\right)$ were measured onboard the Falcon aircraft using two condensation particle counters (CPC, TSI models 3760A and 3010). The number concentration of non-volatile particles $\left(D_{\mathrm{p}}>14 \mathrm{~nm}\right)$ was measured using an additional CPC with a thermodenuder inlet set to a temperature of $250^{\circ} \mathrm{C}$ (Burtscher et al., 2001). The total particle and non-volatile residual size distributions were measured in the dry size range $D_{\mathrm{p}} \sim 0.16-6 \mu \mathrm{m}$ using a Passive Cavity Aerosol Spectrometer Probe-100X (PCASP; e.g. Liu et al., 1992) and Grimm Optical Particle Counter (OPC), respectively. CPC and PCASP measurements were used to calculate particle number concentrations in three size ranges $4-10 \mathrm{~nm}, 10$ $160 \mathrm{~nm}$ and $160-1040 \mathrm{~nm}$ that are roughly representative of the nucleation, Aitken and accumulation mode size classes, respectively. Measurements from 15 flights have been used in this study; the tracks of these flights are shown in Fig. 1 (flight sections where the altitude of the aircraft was at or below $2000 \mathrm{~m}$ a.s.l. are shown in bold).

The IOP also included spatially extensive surface-based measurements from the European Supersites for Atmospheric Aerosol Research (EUSAAR; www.eusaar.net) and from the German Ultrafine Aerosol Network (GUAN; Birmili et al., 2009). The 15 ground sites selected for this study (see Table 1 and Fig. 1) are spread across Europe and include coastal, boreal forest, mountain, and rural environments, and sample a range of air masses from polluted to remote continental and marine. A brief description of each site is given 
Table 1. Summary of surface observation sites used in this study. Site descriptions are based on the information provided by EUSAAR (www.eusaar.net) and on the site-categorisation of Henne et al. (2010).

\begin{tabular}{|c|c|c|c|c|}
\hline Ground site & Acronym & $\begin{array}{l}\text { Altitude } \\
\text { (m a.s.l.) }\end{array}$ & $\begin{array}{c}\text { Aerosol } \\
\text { instrument }\end{array}$ & Description \\
\hline $\begin{array}{l}\text { Aspvreten, } \\
\text { Sweden }\end{array}$ & ASP & 30 & DMPS & $\begin{array}{l}\text { Boreal forest environment. Representative of } \\
\text { regional background in Mid-Sweden. }\end{array}$ \\
\hline $\begin{array}{l}\text { Cabauw, } \\
\text { the Netherlands }\end{array}$ & CBW & 60 & SMPS & $\begin{array}{l}\text { Rural polluted environment. Air masses range } \\
\text { from clean maritime to continental polluted. }\end{array}$ \\
\hline $\begin{array}{l}\text { Finokalia, } \\
\text { Greece }\end{array}$ & FKL & 250 & SMPS & $\begin{array}{l}\text { Coastal environment. Air masses are representative } \\
\text { of synoptic scale atmospheric composition. }\end{array}$ \\
\hline $\begin{array}{l}\text { Hohenpeissen- } \\
\text { berg, Germany }\end{array}$ & НРB & 980 & SMPS & $\begin{array}{l}\text { Rural environment. Representative of continental } \\
\text { background air masses. }\end{array}$ \\
\hline $\begin{array}{l}\text { Hyytiälä, } \\
\text { Finland }\end{array}$ & HTL & 181 & DMPS & $\begin{array}{l}\text { Remote, boreal forest environment. Air masses are } \\
\text { dominated by European pollution but at times very } \\
\text { clean Arctic air. }\end{array}$ \\
\hline $\begin{array}{l}\text { Jungfraujoch, } \\
\text { Switzerland }\end{array}$ & JFJ & 3580 & SMPS & $\begin{array}{l}\text { Remote, high altitude site. Representative of } \\
\text { background air masses above a continental area. }\end{array}$ \\
\hline $\begin{array}{l}\text { JRC-Ispra, } \\
\text { Italy }\end{array}$ & JRC & 209 & DMPS & $\begin{array}{l}\text { Semi-rural polluted environment. Representative } \\
\text { of polluted continental background air masses. }\end{array}$ \\
\hline $\begin{array}{l}\text { K-puszta, } \\
\text { Hungary }\end{array}$ & KPO & 125 & DMPS & $\begin{array}{l}\text { Rural environment. Representative of regional } \\
\text { background in Central-Eastern Europe. }\end{array}$ \\
\hline $\begin{array}{l}\text { Košetice, } \\
\text { Czech Republic }\end{array}$ & KTC & 534 & SMPS & $\begin{array}{l}\text { Rural environment. Representative of continental } \\
\text { background air masses. }\end{array}$ \\
\hline $\begin{array}{l}\text { Mace Head, } \\
\text { Ireland }\end{array}$ & MHD & 5 & SMPS & $\begin{array}{l}\text { Remote, coastal environment. Representative of } \\
\text { relatively clean background marine air masses. }\end{array}$ \\
\hline $\begin{array}{l}\text { Melpitz, } \\
\text { Germany }\end{array}$ & MPZ & 87 & DMPS & $\begin{array}{l}\text { Rural environment. Representative of rural } \\
\text { polluted continental air masses. }\end{array}$ \\
\hline $\begin{array}{l}\text { Monte Cimone, } \\
\text { Italy }\end{array}$ & MTC & 2165 & DMPS & $\begin{array}{l}\text { High altitude site. Representative of free troposphere } \\
\text { for South Europe/North Mediterranean area. }\end{array}$ \\
\hline $\begin{array}{l}\text { Puy de Dôme, } \\
\text { France }\end{array}$ & PDD & 1465 & SMPS & $\begin{array}{l}\text { High altitude site. Representative of regional } \\
\text { (polluted) atmospheric background air masses. }\end{array}$ \\
\hline $\begin{array}{l}\text { Schauinsland, } \\
\text { Germany }\end{array}$ & SLD & 1205 & SMPS & $\begin{array}{l}\text { Mountain ridge site (night-time site is usually above } \\
\text { BL, daytime site is mostly within BL), rural } \\
\text { environment. Representative of continental } \\
\text { background air masses. }\end{array}$ \\
\hline $\begin{array}{l}\text { Vavihill, } \\
\text { Sweden }\end{array}$ & VHL & 172 & DMPS & $\begin{array}{l}\text { Rural environment. Representative of continental } \\
\text { background air masses. }\end{array}$ \\
\hline
\end{tabular}

in Table 1. More detailed information on the location of each site and the particle number concentrations observed can be found in the overview article of Asmi et al. (2011).

Diurnal variation of BL height means that the high-altitude mountain sites may not be located in the BL at all times. Therefore, without detailed screening, measurements at these sites will not be fully representative of aerosol in the European BL. Although this study focuses on the BL, it is important to include these measurements to obtain a detailed overview of aerosol number concentrations over Europe during the IOP. Variations in BL height are simulated in the model used here, but have not been evaluated specifically at the ground sites in this study. In addition to variations in BL height, the particle number concentrations measured at mountain sites may also be influenced by thermal winds or forced convection (Weingartner et al., 1999; Venzac et al., 2009), resulting in diurnal cycles in aerosol, which a relatively coarse resolution global model, like the one used here, is unable to capture. 


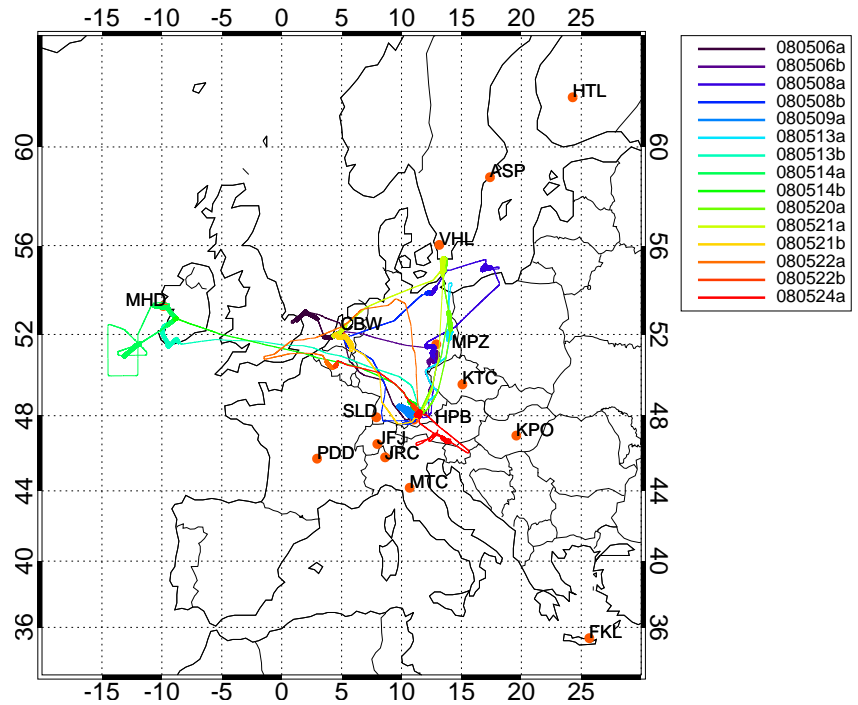

Fig. 1. Map of flight tracks performed by the DLR Falcon 20 research aircraft during the EUCAARI-LONGREX field campaign in May 2008. Sections of the DLR Falcon flight tracks that are at or below $2 \mathrm{~km}$ are shown in bold. Orange dots mark the locations of the European Supersites for Atmospheric Aerosol Research (EUSAAR) and the German Ultrafine Aerosol Network (GUAN) ground sites with aerosol number size distribution measurements for May 2008 (site acronyms are listed in Table 1).

Measurements of the aerosol particle number size distribution were made using either a Scanning (SMPS) or Differential Mobility Particle Spectrometer (DMPS) (e.g. Wang and Flagan, 1990) with minimum detection limits in the diameter range $3-13 \mathrm{~nm}$. Most instruments were operated according to the EUSAAR recommendations for mobility spectrometers (Wiedensohler et al., 2010), which ensure a maximum comparability of the data collected at different measurement sites. A particular requirement is particle sizing at low relative humidities $(<40 \%)$. A Europe-wide intercomparison of instruments by the same authors showed that under defined laboratory conditions, the number size distributions of such instruments were equivalent within $\pm 10 \%$ for the diameter range $20-200 \mathrm{~nm}$. Below $20 \mathrm{~nm}$ the uncertainty increases considerably. To reduce the uncertainty in the observations, we restrict our analysis to the measured number size distribution above $15 \mathrm{~nm}$. Total particle number concentrations with $D_{\mathrm{p}}>15 \mathrm{~nm}$ were calculated from the observed size distribution.

To compare the model to the aircraft and surface observations, we linearly interpolate the simulated data along the flight path of the aircraft and to the horizontal location of the ground site (using the model level corresponding to the altitude of the site). The same minimum cut-off size of the instruments (see above) is also applied to the model. Prior to analysis, simulated data corresponding to periods of missing measurement data were removed. All particle number concentrations are reported at ambient temperature and pressure.
To compare model and observations we use the normalised mean bias (NMB) statistic:

$\operatorname{NMB}(\%)=\frac{\sum_{i=1}^{n}\left(\mathrm{~S}_{i}-\mathrm{O}_{i}\right)}{\sum_{i=1}^{n} \mathrm{O}_{i}} \times 100$

where $\mathrm{S}_{i}$ and $\mathrm{O}_{i}$ are the simulated and observed particle number concentrations, respectively. For comparison with the aircraft and surface observations over the IOP, the NMB, correlation coefficient $\left(R^{2}\right)$, and slope of the linear regression $(m)$ are calculated between the campaign-mean modelled and observed number concentration from each flight or each ground site, $i$. In addition, we calculate the NMB and $R^{2}$ between the hourly-mean observed and simulated number concentrations at each ground site (where $i$ represents the hour), denoted by $\mathrm{NMB}_{\text {hourly }}$ and $R_{\text {hourly }}^{2}$.

\subsection{Synoptic conditions}

During the first half of the IOP ( 1-15 May 2008, hereafter Period A) the meteorological conditions over Central Europe were dominated by a relatively static anticyclonic blocking event. Relatively dry and stable conditions led to an accumulation of European aerosol pollution inside the BL within the centre of the high pressure system (Hamburger et al., 2011). High particle number concentrations were observed at the surface during Period A (see Sect. 4.4). The synoptic conditions during the second half of the IOP $(\sim 16-31$ May 2008, hereafter Period B) were dominated by passage of a number of frontal systems over Central Europe. These systems resulted in an increase in precipitation and a reduction in both the condensation sink and particle number concentrations, observed at the majority of the Central European ground sites. Hamburger et al. (2011) provide a more detailed description of the synoptic and pollution situation over Europe during May 2008.

\section{Model description}

The Global Model of Aerosol Processes (GLOMAP) (Spracklen et al., 2005a,b) simulates the evolution of size and composition resolved aerosols, including their interaction with trace gases and clouds. The host model for GLOMAP is the TOMCAT global 3-D off-line Eulerian chemical transport model (CTM) (Chipperfield, 2006). Large scale atmospheric transport and meteorology in TOMCAT is specified from European Centre for Medium-Range Weather Forecasts (ECMWF) analyses, updated every $6 \mathrm{~h}$. Turbulent mixing in the BL and BL height are calculated using the parameterisation of Holtslag and Boville (1993). All the results have a horizontal resolution of $2.8^{\circ} \times 2.8^{\circ}$ and 31 vertical levels between the surface and $10 \mathrm{hPa}$. The vertical resolution in the $\mathrm{BL}$ ranges from $\sim 60 \mathrm{~m}$ near the surface to $\sim 400 \mathrm{~m}$ at $\sim 2 \mathrm{~km}$ a.s.1.

Here, we use GLOMAP-bin in which the aerosol size distribution is specified in terms of a two-moment sectional 
(bin) scheme with 20 bins spanning $3 \mathrm{~nm}$ to $10 \mu \mathrm{m}$ dry diameter. The aerosol particles undergo microphysical processes (coagulation, condensational growth and in-cloud processing) that alter the aerosol number size distribution in the model. The processes of dry deposition and in-cloud/belowcloud aerosol scavenging and deposition act to remove the aerosol particles. In the following sections, we describe the features of the model that are relevant to this study. For a more detailed model description see Spracklen et al. (2005a,b).

\subsection{Gas-phase emissions and chemistry}

$\mathrm{SO}_{2}$ emissions are from industrial, power-plant, domestic, shipping, road transport, and off-road sources following Cofala et al. (2005) and from volcanic sources from Andres and Kasgnoc (1998). Oceanic emissions of DMS are calculated using the database of Kettle and Andreae (2000) and the seato-air transfer velocity according to Nightingale et al. (2000). Gas-phase sulphuric acid is calculated using a simplified sulphur cycle scheme based on 7 reactions involving $\mathrm{SO}_{2}$, DMS, MSA and other minor species (Spracklen et al., 2005a). Concentrations of oxidants $\mathrm{OH}, \mathrm{O}_{3}$ and $\mathrm{NO}_{3}$ and $\mathrm{HO}_{2}$ are specified using 6-hourly monthly-mean 3-D gridded concentration fields from a TOMCAT simulation with detailed tropospheric chemistry (Arnold et al., 2005). The oxidants are read in at 6$\mathrm{h}$ intervals and linearly interpolated onto the model timestep. Emissions of biogenic terpenes are specified by the GEIA inventory (Benkovitz et al., 1996) and are based on Guenther et al. (1995).

\subsection{Primary particles}

We include emissions of primary carbonaceous aerosol from anthropogenic sources (fossil fuel (FF) and biofuel (BF) burning) following Bond et al. (2004); and biomass burning following van der Werf et al. (2003). There are some difficulties in defining the type of carbonaceous species in an aerosol model since the definition is based upon the measurement technique e.g. light absorption. The carbonaceous aerosol fraction is defined by Bond et al. (2004) to consist of: black carbon (BC; the mass of combustion-generated, $\mathrm{sp}^{2}$ bonded carbon that absorbs the same amount of light as the emitted particles) and organic carbon (OC), simply the mass of carbon that is not BC. It is important to note that Bond et al. (2004) treat all elemental carbon measurements as BC. Henceforth, we refer to the carbonaceous combustion aerosol as $\mathrm{BC}+\mathrm{OC}$.

Emission inventories of $\mathrm{BC}+\mathrm{OC}$ particles used in large scale models are typically mass based (e.g. Cooke et al., 1999; Bond et al., 2004). To estimate the emitted particle number concentration, size resolving models typically assume that particles are emitted with a fixed log-normal size distribution with a specified peak number concentration (number median diameter, $D$ ) and distribution width (stan- dard deviation, $\sigma$ ). The assumption of an initial size distribution for primary particles in global models accounts for both the size of particles at emission and sub-grid scale aerosol processes and dynamics that influence the size and number concentrations of particles shortly after emission (Jacobson and Seinfeld, 2004; Pierce et al., 2009). The assumed lognormal size distribution is also necessary to account for the large variability in the emission size of primary carbonaceous particles from different sources (e.g. Bond et al., 2006, Table 3). In GLOMAP, the primary particles are "emitted" assuming an initial size distribution and then the size and number of particles are allowed to evolve during atmospheric transport.

The choice of the effective emission size distribution in models is crucial since it not only governs the emitted particle number concentrations, but also affects microphysical aerosol processes that are size-dependent. However, there is a large range in values assumed by modellers for $D$ (mass median diameters for $\mathrm{BC}$ and $\mathrm{OC}$ range from $\sim 25$ to $\sim 850 \mathrm{~nm}$, Textor et al., 2006). This range has important implications for the simulated number concentrations of primary BC+OC particles (e.g. Spracklen et al., 2010), and predicted climate-relevant quantities such as $\mathrm{CCN}$ and aerosol optical depth, therefore increasing the uncertainty in estimates of aerosol radiative forcing (Bauer et al., 2010). As far as the authors are aware, recommended values of $D$ and $\sigma$ specifically for large-scale models have only been provided by Dentener et al. (2006) as part of the Aerosol Intercomparison project (AEROCOM; http://nansen.ipsl.jussieu. fr/AEROCOM/). Grid-level and size-resolved particulate emission factors for traffic sources have been provided by Zhang et al. (2005), but the grid scale used $(\sim 300 \mathrm{~m})$ is far smaller than the grid box size of most large-scale models.

One aim of our study is to test the sensitivity of the modelled aerosol over Europe to the size distribution of the emitted anthropogenic and wildfire $\mathrm{BC}+\mathrm{OC}$. Keeping the emission mass fixed, we test two sets of parameters for the lognormal size distribution that are widely used in global aerosol modelling (shown in Fig. 2): those recommended by AEROCOM (fossil fuel emissions: $D_{\mathrm{FF}}=30 \mathrm{~nm}, \sigma_{\mathrm{FF}}=1.8$; wildfire and biofuel emissions: $D_{\mathrm{BF}}=80 \mathrm{~nm}, \sigma_{\mathrm{BF}}=1.8$ ) (Dentener et al., 2006); and those used by Stier et al. (2005) $\left(D_{\mathrm{FF}}=60 \mathrm{~nm}, \sigma_{\mathrm{FF}}=1.59 ; D_{\mathrm{BF}}=150 \mathrm{~nm}, \sigma_{\mathrm{BF}}=1.59\right)$. The factor $\sim 2$ difference in the recommended values for $D \mathrm{im}$ plies very different $\mathrm{BC}+\mathrm{OC}$ number concentrations (for fixed mass); AEROCOM requiring emitted number concentrations to be a factor $\sim 8$ higher than Stier et al. (2005) for fossil fuels.

The emission size distribution used by Stier et al. (2005) has been adapted from AEROCOM recommendations to fit the standard deviation of the size modes in their model. As a result, the spread of the primary distribution in Stier et al. (2005) $(\sigma=1.59)$ is considerably smaller than the spread of the AEROCOM-recommended distribution $(\sigma=1.8)$. Reducing the spread of the assumed emission size distribution 


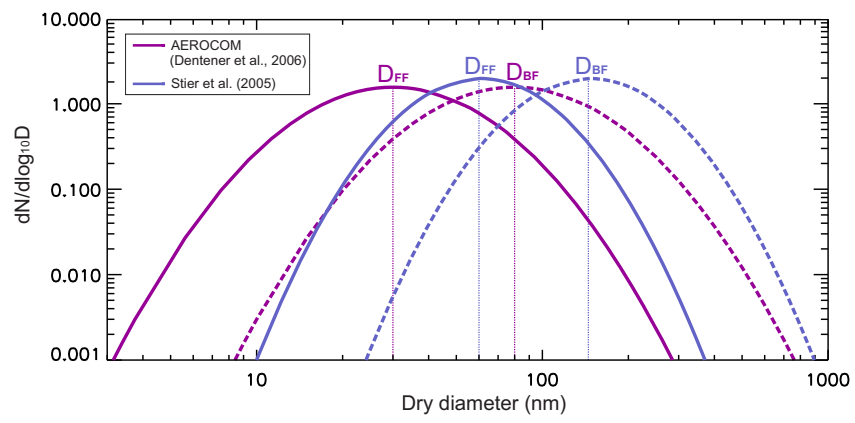

Fig. 2. Normalised log-normal size distributions used in GLOMAP to calculate carbonaceous particle number concentrations from fossil fuel (FF; solid line) and biofuel (BF; dashed line) emissions. Shown are two sets of log-normal size distribution parameters (number median diameter $(D)$ and standard deviation) from AEROCOM (Dentener et al., 2006) and Stier et al. (2005) that are widely used in global aerosol modelling.

from $\sigma=1.8$ to $\sigma=1.59$, increases the emitted number concentration by a factor of $\sim 1.8$, if $D$ were constant. It is important to note that in GLOMAP-bin, we are free to specify any shape distribution within the resolution offered by the 20 size bins, but use the two values of $\sigma$ as specified above. The difference in the parameters assumed by Stier et al. (2005) and Dentener et al. (2006) corresponds to an overall factor $\sim 4.4$ difference in the emitted number concentrations of fossil fuel $\mathrm{BC}+\mathrm{OC}$ particles.

The mean size of primary FF emissions recommended by Dentener et al. (2006) $\left(D_{\mathrm{FF}}=30 \mathrm{~nm}\right)$ is based on kerbside and urban background measurements in several European cities (Putaud et al., 2004; Van Dingenen et al., 2004), where traffic-related number size distributions were dominated by a mode at $D_{\mathrm{p}}=20-30 \mathrm{~nm}$. Although the emitted mass is generally conserved during transport and dispersion over the GLOMAP grid box ( $\sim 200 \mathrm{~km}$ at European latitudes), the number size distribution of primary particles shortly after emission can be altered significantly by (sub-grid scale) atmospheric dynamic processes such as dilution, condensational growth, heterogeneous and self-coagulation, evaporation, and nucleation (e.g. Kittelson, 1998; Wehner et al., 2002; Zhu et al., 2002; Zhang and Wexler, 2004; Zhang et al., 2004; Roldin et al., 2010). Explicit modelling of these subgrid-scale processes would be too computationally expensive for a global CTM, which is why an assumption of an initial size distribution is necessary for primary $\mathrm{BC}+\mathrm{OC}$ particles.

The sub-grid evolution of the primary carbonaceous particle size distribution makes it difficult to constrain the initial size and particle number concentration appropriate for emission of $\mathrm{BC}+\mathrm{OC}$ particles in a large model grid box from measurements obtained relatively close to the emission source. An $85 \%$ increase in particle diameter from the street canyon to the urban background was observed by Wehner et al. (2002), which suggests the mean size of primary particles is likely to increase over the model grid box from the mode diameter measured at the kerbside $\left(D_{\mathrm{FF}}=30 \mathrm{~nm}\right)$. In addition, the statistical analysis of multiple-site observations by Costabile et al. (2009) revealed that the coupling of urban and rural number size distributions is very strong in the mass-dominating accumulation mode range, but only modest in the Aitken mode range.

The size distribution of primary $\mathrm{BC}+\mathrm{OC}$ particle emissions averaged over the model grid box is likely to be more representative of the evolved size distribution of primary carbonaceous aerosol measured at rural background sites. It is important to note, however, that the grid-box mean size distribution will not necessarily correspond to the measured particle size at point locations. Measurement sites will be located at varying distances from aerosol emission sources which means the average processing time of the primary aerosol will also vary between sites, thereby influencing the physical properties of the particles measured. At sites where the observed particles are generally less processed than at other sites, assuming a smaller initial size for $\mathrm{BC}+\mathrm{OC}$ particles may agree better with the observations and vice versa.

We encounter further uncertainty associated with the assumed size distribution for primary $\mathrm{BC}+\mathrm{OC}$ emissions when we consider the composition of the emitted particles. Many aerosol models assume a homogeneous size distribution for emitted primary BC and OC (e.g. Stier et al., 2005; Textor et al., 2006, Table 4 and references therein), but the median sizes of the $\mathrm{BC}$ and $\mathrm{OC}$ components are likely to differ in reality. The traffic-related ultrafine mode in the range $D_{\mathrm{p}} \sim 3-$ $30 \mathrm{~nm}$ is thought to be mostly made up of semi-volatile organic compounds formed during dilution and rapid cooling of exhaust emission gases (Kittelson, 1998; Baltensperger et al., 2002). These particles may also contain carbon compounds (Kittelson, 1998), and can be broadly classed as primary organic matter (or OC) in the model. On the other hand, the peak emission diameter of the primary soot (BC) component is more likely to be around $\sim 50 \mathrm{~nm}$ or larger as observed by Baltensperger et al. (2002). A second mode, with a maximum in the range $D_{\mathrm{p}} \sim 40-120 \mathrm{~nm}$, is observed in on-road, kerbside, and urban background number size distributions (e.g. Kittelson et al., 2000, 2006; Geller et al., 2005; Casati et al., 2007; Wehner et al., 2009; Weimer et al., 2009) and is associated with direct emissions of soot (BC) particles from diesel and gasoline vehicles (e.g. Harris and Maricq, 2001).

Indications of the number concentration and size of primary particles from combustion sources (such as soot) can also be gathered from the non-volatile residues of the particle number size distribution (e.g. Wehner et al., 2004; Rose et al., 2006; Engler et al., 2007; Birmili et al., 2010). In the urban atmosphere of Augsburg, Birmili et al. (2010) identified a clear non-volatile particle mode having a geometric mean diameter between 60 and $90 \mathrm{~nm}$ in number representation and around $200 \mathrm{~nm}$ in volume representation, which Rose et al. (2006) suggest is representative of direct 
vehicular soot emissions. Engler et al. (2007) observe 23 non-volatile modes in the rural background particle number size distribution, but the mode they associate with primary emissions from combustion has typical modal diameters between $\sim 70$ and $90 \mathrm{~nm}$. These observations suggest that although atmospheric processes (such as dilution with the background aerosol and/or aerosol dynamical processes) remove the number distribution fingerprint of urban primary emissions, the mode diameter of combustion generated soot particles remains roughly between $\sim 50$ and $\sim 90 \mathrm{~nm}$ moving from the urban environment to the rural background.

The measurement studies discussed above suggest that the peak emission diameter of the $\mathrm{BC}$ component of traffic emissions is larger than the log-normal mode diameter recommended by Dentener et al. (2006) for fossil fuel sources, and that the mode diameter used by Stier et al. (2005) $\left(D_{\mathrm{FF}}=60 \mathrm{~nm}\right)$ may be more suitable. Yu and Luo (2009) come to a similar conclusion about both the FF and $\mathrm{BF}$ emission sizes recommended by AEROCOM and assume values of $D_{\mathrm{FF}}=60 \mathrm{~nm}$ and $D_{\mathrm{BF}}=150 \mathrm{~nm}(\sigma=1.8)$. However, assuming a larger emission size that is consistent with measurements of primary $\mathrm{BC} /$ non-volatile particles may neglect possible contributions to the total size distribution from ultrafine particles formed via homogeneous nucleation and condensation processes in the vehicle exhaust (e.g. AbdulKhalek et al., 2000) and/or combustion-generated nanoparticles of OC (e.g. Sgro et al., 2008). It is important to note that we class particles formed via homogeneous nucleation shortly after emission (either in the vehicle tailpipe or in the emission plume) as primary particles in the model, since they are formed from emitted precursor gases on sub-grid scales. With atmospheric dilution, semi-volatile particles produced via this process may undergo gas-to-particle partitioning; involving evaporation and possible re-condensation onto surfaces of larger particles in the exhaust plume e.g. soot or background aerosol (e.g. Zhu et al., 2002; Zhang et al., 2004). These processes make it difficult to quantify their contribution to the average $\mathrm{BC}+\mathrm{OC}$ number size distribution over the model grid box.

The appropriate emission size distribution to assume for primary carbonaceous particles in a global model remains ambiguous. However, since the emission size distributions used by Stier et al. (2005) and Dentener et al. (2006) are representative of how the global aerosol modelling community treats the emission of carbonaceous aerosol; we use them here in our sensitivity study. We therefore have two scenarios for the size of $\mathrm{BC}+\mathrm{OC}$ particles at emission: small particles (BCOC_sm; AEROCOM, Dentener et al., 2006) and large particles (BCOC_lg; Stier et al., 2005). The emitted number concentrations predicted by these two experiments can be viewed as rough upper and lower limits to the modelled primary $\mathrm{BC}+\mathrm{OC}$ particle number concentration.

To account for sub-grid production of sulphate particulates, we assume that $2.5 \%$ of $\mathrm{SO}_{2}$ from anthropogenic and volcanic sources is emitted as sulphuric acid particles.
We use the size distribution for primary sulphate modified by Stier et al. (2005) from AEROCOM recommendations for the year 2000 (Dentener et al., 2006) (road transport: $D=60 \mathrm{~nm}, \sigma=1.59$; shipping, industry and power-plant emissions: $50 \%$ at $D=150 \mathrm{~nm}, \sigma=1.59$ and $50 \%$ at $D=$ $1.5 \mu \mathrm{m}, \sigma=2.0$; wildfire, biofuel and volcanic emissions: $50 \%$ at $D=60 \mathrm{~nm}$ and $50 \%$ at $D=150 \mathrm{~nm}, \sigma=1.59$ ). Primary sea spray emissions are also included and are based on Gong et al. (2003).

\subsection{Formation of secondary particles}

A simple scheme for the formation of oxidised biogenic organic compounds or secondary organic aerosol (SOA) is included in all model simulations in this study. This process involves the reaction of biogenic monoterpenes with $\mathrm{O}_{3}$, $\mathrm{OH}$ and $\mathrm{NO}_{3}$ (assuming the reactivity of alpha-pinene) to form a gas-phase oxidation product with a $13 \%$ molar yield (Spracklen et al., 2006). This first stage oxidation product can form SOA through condensing with zero vapour pressure onto pre-existing aerosol (Spracklen et al., 2006, 2008). Anthropogenic volatile or intermediate-volatile organic compounds are also known to contribute to SOA formation (e.g. Robinson et al., 2007; Henze et al., 2008), but we do not consider their contribution in this study.

The role of ammonium nitrate aerosol is not simulated in GLOMAP. We recognise that the contribution of nitrate aerosol may be important for accumulation-mode particle number concentrations but only towards the top of the BL, where partitioning of semi-volatile gas phase species to the particle phase occurs at reduced temperature and enhanced relative humidity (Morgan et al., 2010). We therefore assume that the contribution to the total particle size distribution is fairly small at the majority of the ground sites.

Secondary sulphate particles are formed through two mechanisms: binary homogeneous nucleation (BHN) of $\mathrm{H}_{2} \mathrm{SO}_{4}-\mathrm{H}_{2} \mathrm{O}$ (Kulmala et al., 1998) to simulate nucleation in the FT; and an empirical particle formation mechanism based on $\mathrm{H}_{2} \mathrm{SO}_{4}$ specifically to capture nucleation events observed in the BL (Kulmala et al., 2006; Sihto et al., 2006). Previous GLOMAP studies have shown good agreement with observations at marine, continental and FT mountain sites using a combination of BHN and an empirical activation or kinetic nucleation mechanism in the BL (Spracklen et al., 2006, 2008, 2010). In Metzger et al. (2010), we tested an empirical nucleation mechanism involving low-volatility organic vapour in addition to $\mathrm{H}_{2} \mathrm{SO}_{4}$, which showed very good agreement for the whole vertical profile of observed particle number concentrations, without being restricted to the BL.

In this study, we test four nucleation mechanisms (summarised in Table 2) intended to capture nucleation events observed in the BL, while allowing BHN to occur throughout the atmosphere in all model simulations. The activation mechanism (ACT) is described by:

$J_{\text {nuc }}=A\left[\mathrm{H}_{2} \mathrm{SO}_{4}\right]$ 
The sulphuric acid kinetic mechanism (KIN) is described by:

$J_{\text {nuc }}=K\left[\mathrm{H}_{2} \mathrm{SO}_{4}\right]^{2}$

The combined organic and sulphuric acid (kinetic-type) mechanism of Metzger et al. (2010), which we call here, ORG1, is described by:

$J_{\text {nuc }}=k\left[\mathrm{H}_{2} \mathrm{SO}_{4}\right][$ organic $]$

We assume that the concentration of organic vapour ([organic]) can be represented by the the gas-phase concentration of the first stage oxidation product of monoterpenes (described above). We also test a new empirical mechanism of Paasonen et al. (2010) involving kinetic-type nucleation of sulphuric acid both homomolecularly and heteromolecularly with low-volatility organic vapours, which we term ORG2:

$J_{\text {nuc }}=k_{1}\left[\mathrm{H}_{2} \mathrm{SO}_{4}\right]^{2}+k_{2}\left[\mathrm{H}_{2} \mathrm{SO}_{4}\right][$ organic $]$

For this study, we have restricted the ACT and KIN nucleation mechanisms to the model BL, but allow the ORG1 and ORG2 mechanisms to occur throughout the atmosphere.

The nucleation rate coefficients (see Table 2) for the ACT and KIN mechanisms have been constrained with worldwide observations (Spracklen et al., 2010) and lie within the range derived independently from measurements of particle formation events at European ground sites (Riipinen et al., 2007). The rate coefficients for the ORG1 and ORG2 mechanisms are consistent with the studies of Metzger et al. (2010) and Paasonen et al. (2010), respectively. The value of the rate coefficient is fixed globally in any simulation.

To take into account scavenging losses of freshly nucleated clusters and condensable gases during growth in the BL nucleation model simulations, the production rate of measureable particles (or "apparent" nucleation rate, $J_{\text {app}}$ ) is controlled in the model by the cluster formation rate $\left(J_{\text {nuc }}\right)$ and the pre-existing particle surface area following the approximation of Kerminen and Kulmala (2002):

$J_{\text {app }}=J_{\text {nuc }} \exp \left[0.23\left(\frac{1}{d_{\text {app }}}-\frac{1}{d_{\text {crit }}}\right) \frac{\mathrm{CS}^{\prime}}{\mathrm{GR}}\right]$

where $d_{\text {app }}(\mathrm{nm})$ is the diameter of the measureable particles (here we assume $d_{\mathrm{app}}=3 \mathrm{~nm}$ ) and $d_{\text {crit }}(\mathrm{nm})$ is the diameter of the critical cluster. We assume $d_{\text {crit }}=0.8 \mathrm{~nm}$ for the ACT and KIN mechanisms and assume sizes of $1.5 \mathrm{~nm}$ and $2 \mathrm{~nm}$ for the ORG1 and ORG2 mechanisms as used by Metzger et al. (2010) and Paasonen et al. (2010), respectively. The growth rate of the nucleated clusters, GR $\left(\mathrm{nm} \mathrm{h}^{-1}\right)$, is assumed to be constant between $d_{\text {crit }}$ and $d_{\text {app }}$. The reduced condensation sink, $\mathrm{CS}^{\prime}\left(\mathrm{m}^{-2}\right)$, is calculated by integrating over the aerosol size distribution (Kulmala et al., 2001). In the model, $\mathrm{CS}^{\prime}$ is calculated by summing over the aerosol size bins $j$ (Spracklen et al., 2006):

$\mathrm{CS}^{\prime}=\sum_{j} \beta_{j} r_{j} N_{j}$ where $\beta_{j}$ is the transitional correction for the condensational mass flux (Fuchs and Sutugin, 1971), $r_{j}$ is the particle radius and $N_{j}$ is the particle number concentration. The condensation sink, $\mathrm{CS}\left(\mathrm{s}^{-1}\right)$, is calculated using $\mathrm{CS}^{\prime}$ :

$\mathrm{CS}=4 \pi D_{\mathrm{C}} \mathrm{CS}^{\prime}$

where $D_{\mathrm{C}}$ is the vapour diffusion coefficient. Once a cluster has formed, subsequent growth in the model arises from condensation of sulphuric acid vapour up to a particle size of $3 \mathrm{~nm}$ and then growth to larger sizes through the condensation of both sulphuric acid and SOA (Spracklen et al., 2006). Nucleated particles are added to the model at $3 \mathrm{~nm}$ diameter.

\subsection{Set-up of aerosol distributions}

The aerosol distribution set-up used in this study has been modified from that used in e.g. Spracklen et al. (2006, $2008,2010)$ so as to track the number concentration of nonvolatile (BC-containing) particle cores separately from the other species for comparison with observations. We note that sea salt particles also contribute to the non-volatile aerosol fraction as observed at the coastal site, Mace Head (Jennings and O'Dowd, 1990; O'Dowd and Smith, 1993). But for this study, we assume the non-volatile particle number concentration $\left(D_{\mathrm{p}}>14 \mathrm{~nm}\right)$ measured by the DLR Falcon aircraft is dominated by primary BC (soot) particles (Rose et al., 2006; Engler et al., 2007; Birmili et al., 2009) and that the contribution of sea salt particles to the number concentration aloft over continental Europe is relatively small (e.g. Putaud et al., 2004).

The model was set up with two externally mixed particle distributions: distribution 1 contains $\mathrm{BC}, \mathrm{OC}$ and sulphate; and distribution 2 contains sulphate, sea salt, $\mathrm{BC}$, and OC. Primary $\mathrm{BC}+\mathrm{OC}$ particles are emitted into distribution 1 and the particles can grow by irreversible condensation of SOA and $\mathrm{H}_{2} \mathrm{SO}_{4}$, with the SOA being associated with the OC component in the particles. Nucleated particles are emitted into distribution 2, along with primary sulphate and sea spray, but $\mathrm{BC}+\mathrm{OC}$ particles enter only through coagulation with distribution 1 . The smaller particles in this distribution tend to be nucleated sulphate particles and the larger particles are a mixture of all components.

In our previous studies, the $\mathrm{BC}+\mathrm{OC}$ particles in distribution 1 were moved to the equivalent size section of distribution 2 if they accumulated a monolayer of $\mathrm{H}_{2} \mathrm{SO}_{4}$ in one model time step - commonly referred to as a parameterisation of particle ageing. Here, sulphate is allowed to accumulate on particles in distribution 1, and their number concentration is depleted by coagulation with particles in both distributions. Both distributions are treated as hydrophilic and all particles can act as $\mathrm{CCN}$ and undergo wet removal processes. 
Table 2. Summary of the GLOMAP model simulations used in this study. All model simulations include primary aerosol emissions and binary homogeneous nucleation of $\mathrm{H}_{2} \mathrm{SO}_{4}-\mathrm{H}_{2} \mathrm{O}$ (Kulmala et al., 1998) to simulate nucleation in the FT (see Sect. 3 for details). Modelled campaign (May 2008) mean particle number concentrations $\left(D_{\mathrm{p}}>3 \mathrm{~nm}\right)$ in the European BL $(\leq 2000 \mathrm{~m}$ a.s.1.) are given for each simulation. The European domain is considered as the area between the longitudes $\sim 65.6^{\circ} \mathrm{N}$ and $\sim 32.1^{\circ} \mathrm{N}$, and latitudes $\sim 22.5^{\circ} \mathrm{W}$ and $\sim 36.6^{\circ} \mathrm{E}$.

\begin{tabular}{|c|c|c|c|c|}
\hline$\#$ & $\begin{array}{l}\text { Simulation } \\
\text { name }\end{array}$ & $\begin{array}{l}\text { Size distribution of } \\
\text { primary fossil fuel } \\
\text { and biofuel emissions }\end{array}$ & $\begin{array}{l}\text { BL nucleation } \\
\text { mechanism and rate }\end{array}$ & $\begin{array}{l}\text { Mean particle number } \\
\text { concentration in the } \\
\text { European } \mathrm{BL}\left(\mathrm{cm}^{-3}\right)\end{array}$ \\
\hline 1 & BCOC_lg & $\begin{array}{l}\text { Large size: } \\
D_{\mathrm{FF}}=60 \mathrm{~nm} \\
D_{\mathrm{BF}}=150 \mathrm{~nm} \\
\text { (Stier et al., 2005) }\end{array}$ & None & 760 \\
\hline 2 & BCOC_sm & $\begin{array}{l}\text { Small size: } \\
D_{\mathrm{FF}}=30 \mathrm{~nm} \\
D_{\mathrm{BF}}=80 \mathrm{~nm} \\
\text { (Dentener et al., 2006) }\end{array}$ & None & 1483 \\
\hline 3 & ACT-BCOC_lg & $\begin{array}{l}\text { Large size: } \\
D_{\mathrm{FF}}=60 \mathrm{~nm} \\
D_{\mathrm{BF}}=150 \mathrm{~nm} \\
\text { (Stier et al., 2005) }\end{array}$ & $\begin{array}{l}\text { ACT } \\
A=2 \times 10^{-6} \mathrm{~s}^{-1}\end{array}$ & 1350 \\
\hline 4 & ACT-BCOC_sm & $\begin{array}{l}\text { Small size: } \\
D_{\mathrm{FF}}=30 \mathrm{~nm} \\
D_{\mathrm{BF}}=80 \mathrm{~nm} \\
\text { (Dentener et al., 2006) }\end{array}$ & $\begin{array}{l}\text { ACT } \\
A=2 \times 10^{-6} \mathrm{~s}^{-1}\end{array}$ & 1871 \\
\hline 5 & KIN-BCOC_lg & $\begin{array}{l}\text { Large size: } \\
D_{\mathrm{FF}}=60 \mathrm{~nm} \\
D_{\mathrm{BF}}=150 \mathrm{~nm} \\
\text { (Stier et al., 2005) }\end{array}$ & $\begin{array}{l}\mathrm{KIN} \\
K=2 \times 10^{-12} \mathrm{~cm}^{3} \mathrm{~s}^{-1}\end{array}$ & 1868 \\
\hline 6 & KIN-BCOC_sm & $\begin{array}{l}\text { Small size: } \\
D_{\mathrm{FF}}=30 \mathrm{~nm} \\
D_{\mathrm{BF}}=80 \mathrm{~nm} \\
\text { (Dentener et al., 2006) }\end{array}$ & $\begin{array}{l}\mathrm{KIN} \\
K=2 \times 10^{-12} \mathrm{~cm}^{3} \mathrm{~s}^{-1}\end{array}$ & 2226 \\
\hline 7 & ORG1-BCOC_lg & $\begin{array}{l}\text { Large size: } \\
D_{\mathrm{FF}}=60 \mathrm{~nm} \\
D_{\mathrm{BF}}=150 \mathrm{~nm} \\
\text { (Stier et al., 2005) }\end{array}$ & $\begin{array}{l}\text { ORG1 } \\
k=5 \times 10^{-13} \mathrm{~cm}^{3} \mathrm{~s}^{-1}\end{array}$ & 1967 \\
\hline 8 & ORG1-BCOC_sm & $\begin{array}{l}\text { Small size: } \\
D_{\mathrm{FF}}=30 \mathrm{~nm} \\
D_{\mathrm{BF}}=80 \mathrm{~nm} \\
\text { (Dentener et al., 2006) }\end{array}$ & $\begin{array}{l}\text { ORG1 } \\
k=5 \times 10^{-13} \mathrm{~cm}^{3} \mathrm{~s}^{-1}\end{array}$ & 2312 \\
\hline 9 & ORG2-BCOC_lg & $\begin{array}{l}\text { Large size: } \\
D_{\mathrm{FF}}=60 \mathrm{~nm} \\
D_{\mathrm{BF}}=150 \mathrm{~nm} \\
\text { (Stier et al., 2005) }\end{array}$ & $\begin{array}{l}\text { ORG2 } \\
k_{1}=8.2 \times 10^{-15} \mathrm{~cm}^{3} \mathrm{~s}^{-1} \\
k_{2}=7.0 \times 10^{-14} \mathrm{~cm}^{3} \mathrm{~s}^{-1}\end{array}$ & 1670 \\
\hline 10 & ORG2-BCOC_sm & $\begin{array}{l}\text { Small size: } \\
D_{\mathrm{FF}}=30 \mathrm{~nm} \\
D_{\mathrm{BF}}=80 \mathrm{~nm} \\
\text { (Dentener et al., 2006) }\end{array}$ & $\begin{array}{l}\text { ORG2 } \\
k_{1}=8.2 \times 10^{-15} \mathrm{~cm}^{3} \mathrm{~s}^{-1} \\
k_{2}=7.0 \times 10^{-14} \mathrm{~cm}^{3} \mathrm{~s}^{-1}\end{array}$ & 2076 \\
\hline
\end{tabular}




\subsection{Description of model simulations}

The model aerosol fields were generated from an initially aerosol-free atmosphere initialised on 1 February 2008 and spun-up for 90 days to produce a realistic aerosol distribution (Spracklen et al., 2005a). The model was set up to output 3-D fields every hour over a European domain. A wide range of sensitivity runs were completed to understand the effect of uncertainties in the emission size of primary $\mathrm{BC}+\mathrm{OC}$ particles (Sect. 3.2) and in the mechanism and rates of $\mathrm{BL}$ nucleation (Sect. 3.3). The model experiments used in this study are detailed in Table 2 and are split into those with and without BL nucleation.

\section{Results and discussion}

\subsection{Analysis of ground site observations}

In this section, we analyse surface-level aerosol measurements from 15 EUSAAR and GUAN ground sites (Table 1) over the EUCAARI May 2008 campaign. Summary statistics for total particle number concentrations $\left(D_{\mathrm{p}}>15 \mathrm{~nm}\right.$; $\left.N_{\text {tot }}\right)$ and number concentrations in three size ranges typical for CCN; $D_{\mathrm{p}}>50 \mathrm{~nm}\left(N_{50}\right),>100 \mathrm{~nm}\left(N_{100}\right)$, and $>160 \mathrm{~nm}$ $\left(N_{160}\right)$ are given in Table 3.

\subsubsection{Analysis of the monthly-mean particle size distribution}

Figure 3 shows the May 2008 modelled number size distribution averaged over the 15 ground sites. The mean size distribution predicted by model experiments BCOC_sm and BCOC_lg (simulations 1-2, Table 2) is unimodal despite the bimodal emission size distribution of $\mathrm{BC}+\mathrm{OC}$ particles $(\mathrm{BF}$ and $\mathrm{FF}$ emissions; Fig. 2). The primary $\mathrm{BC}+\mathrm{OC}$ particles undergo condensation growth, coagulation, and dry/wet deposition after emission resulting in a modelled size distribution that looks very different from the emitted size distribution. We are therefore not only testing the emitted size of primary carbonaceous aerosol, but the emitted size combined with other microphysical aerosol processes in the model. The size distribution predicted by these experiments will also include contributions from primary emissions of the other simulated aerosol species (sulphate and sea salt), and secondary sulphate particles from BHN.

Figure 4 compares the total modelled and observed campaign-mean number size distribution at each of the ground sites for all model simulations in Table 2. The general shape of the observed size distribution in the range $\sim 80$ $1000 \mathrm{~nm}$ is well reproduced by the primary aerosol experiments, in particular the overlapping Aitken and accumulation modes typically observed at continental BL sites. At the majority of sites, relatively high particle concentrations were observed in the nucleation and lower-Aitken modes.

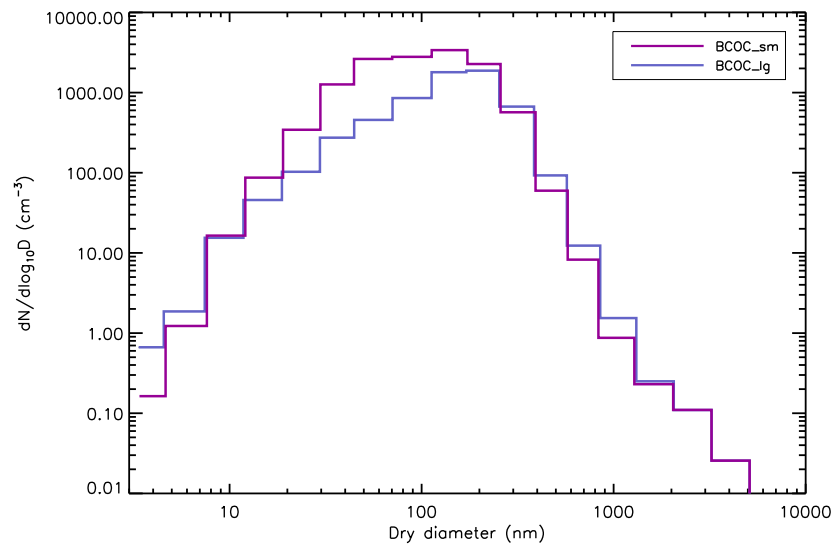

Fig. 3. Campaign-mean modelled total number size distribution averaged over all ground sites in Table 1. Model experiments, BCOC_sm and BCOC_lg, are described in Table 2.

Number concentrations in these size ranges are poorly captured in the experiment with large primary particle emissions (BCOC_lg), resulting in a large negative bias between the modelled and observed multi-site campaign-mean $N_{\text {tot }}$ $(\mathrm{NMB}=-69 \% ; m=0.23)$. The overall spatial pattern of $N_{\text {tot }}$ is captured well with BCOC_lg $\left(R^{2}=0.64\right)$. By reducing the emission size of the primary $\mathrm{BC}+\mathrm{OC}$ particles (BCOC_sm), the negative bias of the model is decreased considerably $(\mathrm{NMB}=-28 \% ; m=0.73)$ and the predicted spatial pattern is improved further $\left(R^{2}=0.71\right)$

Including a BL nucleation mechanism in the model (simulations 3-10, Table 2) increases particle concentrations in the nucleation and Aitken modes at the large majority of sites, leading to better agreement with the observed size distributions at small sizes. In experiment BCOC_lg, the mean modelled $N_{\text {tot }}$ over Europe increases by a factor of $\sim 1.6$ 1.9 , resulting in a smaller model bias of between $-53 \%$ and $-40 \%$ depending on the BL nucleation mechanism (ACT, KIN, ORG1 or ORG2). In the BCOC_sm experiment, the model bias becomes small (range -19 to $-11 \%$ ), particularly with the ORG1 mechanism. When smaller primary particles are emitted, the increase in mean $N_{\text {tot }}$ over Europe from BL nucleation is less pronounced $(\sim 20-30 \%)$ due to the higher number concentration of pre-existing primary particles.

The BCOC_sm experiment tends to agree better with observations of $N_{\text {tot }}$ averaged over the IOP, suggesting higher simulated number concentrations are needed than achieved with the BCOC_lg experiment, despite the large emission size agreeing better with measured roadside and urban BC particle size distributions (Sect. 3.2). Including BL nucleation in the BCOC_lg experiment reduces the low bias of the model, but does not fully explain the shortfall in $N_{\text {tot }}$. In addition, the magnitude of the slope of the linear regression between modelled and observed $N_{\text {tot }}$ remains low ( $m=$ $0.22-0.26)$ and there is a decrease in the spatial correlation between model and observations with the ORG1 $\left(R^{2}=0.35\right)$ 

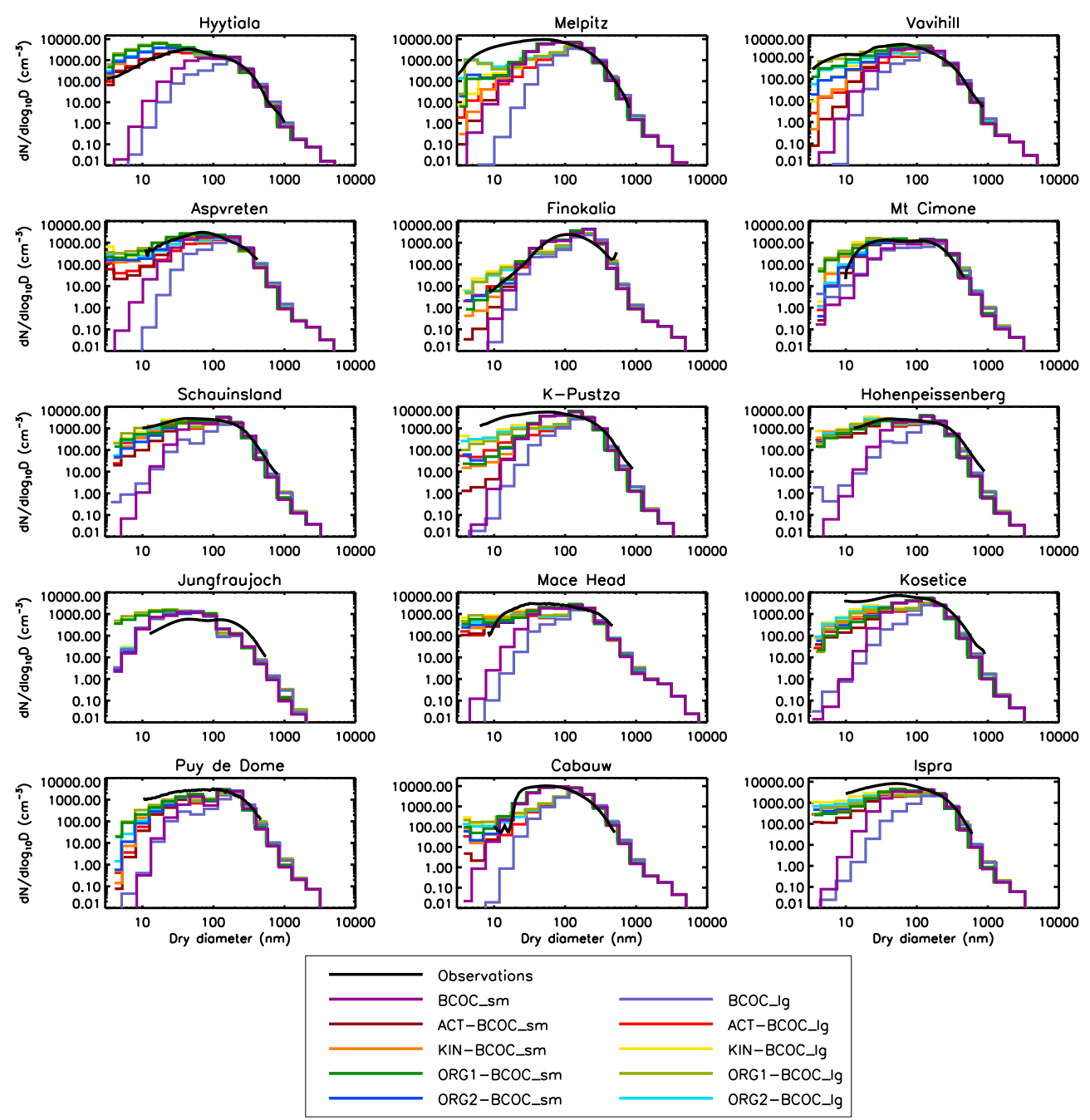

Fig. 4. Campaign-mean simulated (colour) and observed (black) total number size distributions at each ground site. Model experiments listed in the legend are described in Table 2.

and ORG2 $\left(R^{2}=0.59\right)$ mechanisms. These results suggest possible errors in the modelling of nucleation events (discussed in Sect. 4.4), which may be a reason why BL nucleation is unable to explain the shortfall.

The dependence of modelled concentrations on the assumed size of the primary particles decreases with the size of particles being considered. For example, the mean modelled $N_{50}$ increases by $\sim 60 \%$ in the European BL between the BCOC_lg and BCOC_sm experiments, while $N_{100}$ and $N_{160}$ increase by $\sim 45 \%$ and $\sim 20 \%$, respectively. The model simulations without BL nucleation compare well with the observations of $N_{50}, N_{100}$ and $N_{160}$ (Table 3), confirming that the underpediction of $N_{\text {tot }}$ is largely due to an underprediction of number concentrations in the range $15-50 \mathrm{~nm}\left(N_{<50}\right)$. Figure 5 shows the normalised mean bias between hourly-mean modelled and observed $N_{<50}$ and $N_{50}\left(\mathrm{NMB}_{\text {hourly }}\right)$ at each site for the IOP. The spatial pattern of $N_{50}, N_{100}$, and $N_{160}$ over Europe is captured well by the model $\left(R^{2}=0.47-0.86\right)$.
When we assume a small initial size for primary $\mathrm{BC}+\mathrm{OC}$ particles (BCOC_sm), we find good agreement with surface observations of $N_{50}(\mathrm{NMB}=-18 \%, m=0.80)$ and $N_{100}(\mathrm{NMB}=-1 \%, m=0.81)$ averaged over the IOP. With the BCOC $1 \mathrm{lg}$ experiment the model is biased low for $N_{50}$ $(\mathrm{NMB}=-52 \%, m=0.44)$ and $N_{100}(\mathrm{NMB}=-29 \%, m=$ $0.64)$. For $N_{160}$, the model bias is small in experiment BCOC_sm (NMB $=9 \%, m=0.65)$, but in contrast to comparisons with observed $N_{100}, N_{50}$ and $N_{\text {tot }}$, we find the best agreement with observed $N_{160}$ over the IOP is with the $\mathrm{BCOC} \_\mathrm{lg}$ experiment $(\mathrm{NMB}=-1 \%, m=0.74)$.

Including BL nucleation in the model increases the campaign mean $N_{50}$ and $N_{100}$ in the European BL by $23-36 \%$ and $14-20 \%$ respectively in the BCOC_lg experiment, and by $8-12 \%$ and $5-8 \%$ respectively in the BCOC_sm experiment. The increases in particle number concentrations depend on the nucleation mechanism (the smallest increase in $N_{50}$ and $N_{100}$ is achieved with the ACT mechanism; the 
Table 3. Summary statistics for total particle number concentrations $\left(D_{\mathrm{p}}>15 \mathrm{~nm} ; N_{\mathrm{tot}}\right)$ and for concentrations of particles in three sizeranges typical for CCN; $D_{\mathrm{p}}>50 \mathrm{~nm}\left(N_{50}\right),>100 \mathrm{~nm}\left(N_{100}\right)$ and $>160 \mathrm{~nm}\left(N_{160}\right)$. The normalised mean bias (NMB), slope of the linear regression $(m)$ and correlation coefficient $\left(R^{2}\right)$ are calculated between the simulated and observed campaign-mean number concentrations at each ground site.

\begin{tabular}{lrrrrrrrrrrrr}
\hline Model & \multicolumn{4}{c}{ NMB $(\%)$} & \multicolumn{4}{c}{$m$} & \multicolumn{4}{c}{$R^{2}$} \\
Experiment & $N_{\text {tot }}$ & $N_{50}$ & $N_{100}$ & $N_{160}$ & $N_{\text {tot }}$ & $N_{50}$ & $N_{100}$ & $N_{160}$ & $N_{\text {tot }}$ & $N_{50}$ & $N_{100}$ & $N_{160}$ \\
\hline BCOC_lg & -69 & -52 & -29 & -1 & 0.23 & 0.44 & 0.64 & 0.74 & 0.64 & 0.82 & 0.86 & 0.71 \\
BCOC_sm & -28 & -18 & -1 & 9 & 0.73 & 0.80 & 0.81 & 0.65 & 0.71 & 0.86 & 0.77 & 0.47 \\
ACT-BCOC_lg & -53 & -43 & -22 & -1 & 0.24 & 0.44 & 0.65 & 0.75 & 0.68 & 0.87 & 0.83 & 0.69 \\
ACT-BCOC_sm & -19 & -13 & 4 & 10 & 0.71 & 0.82 & 0.83 & 0.67 & 0.72 & 0.86 & 0.76 & 0.49 \\
KIN-BCOC_lg & -43 & -38 & -19 & -1 & 0.26 & 0.45 & 0.66 & 0.74 & 0.63 & 0.88 & 0.81 & 0.71 \\
KIN-BCOC_sm & -13 & -11 & 6 & 9 & 0.70 & 0.80 & 0.84 & 0.67 & 0.71 & 0.87 & 0.77 & 0.49 \\
ORG1-BCOC_lg & -40 & -37 & -17 & -0.1 & 0.22 & 0.45 & 0.68 & 0.73 & 0.35 & 0.87 & 0.82 & 0.65 \\
ORG1-BCOC_sm & -11 & -11 & 7 & 8 & 0.67 & 0.81 & 0.86 & 0.65 & 0.66 & 0.87 & 0.77 & 0.48 \\
ORG2-BCOC_lg & -46 & -40 & -20 & 0.1 & 0.25 & 0.44 & 0.74 & 0.70 & 0.59 & 0.87 & 0.82 & 0.67 \\
ORG2-BCOC_sm & -15 & -12 & 6 & 10 & 0.69 & 0.81 & 0.84 & 0.66 & 0.70 & 0.86 & 0.78 & 0.48 \\
\hline
\end{tabular}

largest with the ORG1 mechanism). These results are similar to the mean enhancements to CCN found by Spracklen et al. (2008); CCN number concentrations at $1 \%$ and $0.2 \%$ supersaturation $(\mathrm{CCN}(0.2 \%))$ were found to increase by $30 \%$ and 6-15\% respectively at European ground sites. Pierce and Adams (2009) also show a 5\% increase in BL CCN $(0.2 \%)$ over Europe when activation BL nucleation is included in their model.

The impact of BL nucleation on CCN-sized particle number concentrations is considerably smaller than for $N_{\text {tot }}$ (given above) and for the total particle number concentration with $D_{\mathrm{p}}>3 \mathrm{~nm}$ (see Table 2, column 5). The dampened response of $N_{50}$ and $N_{100}$ to BL nucleation arises from an increase in coagulation and condensation sinks from an additional source of secondary particles, thereby reducing the survival probability of ultrafine particles and reducing the condensational growth of these particles to CCN sizes (e.g. Pierce and Adams, 2007; Kuang et al., 2009).

Including BL nucleation in the BCOC_lg experiment reduces the negative model bias in $N_{50}$ and $N_{100}$; the smallest bias in both $N_{50}(-37 \%)$ and $N_{100}(-17 \%)$ is achieved with the ORG1 mechanism. In the BCOC_sm experiment, the bias in $N_{50}$ is also reduced by including BL nucleation; the smallest bias $(-11 \%)$ is achieved with the KIN and ORG1 mechanisms. However, for $N_{100}$ all nucleation mechanisms lead to a slightly larger model bias (although the NMB remains smaller than $10 \%$ ). The impact of BL nucleation on $N_{160}$ is fairly negligible (increasing mean concentrations over Europe by less than $1 \%$ ), resulting in small changes in the model bias in this size range.

When BL nucleation is included, there is little improvement (if any) in the slope of the linear regression and correlation coefficient between simulated and observed multi-site campaign-mean $N_{50}, N_{100}$, and $N_{160}$. Without further sup- porting evidence, these results would suggest that the model is able to explain the observed number concentrations of $\mathrm{CCN}$-sized particles averaged over the IOP reasonably well, without the need for BL nucleation, if a small initial size is assumed for emitted $\mathrm{BC}+\mathrm{OC}$ particles.

\subsection{2 $\quad T$-statistics at each ground site}

The NMB between modelled and observed multi-site campaign-mean number concentrations can be misleading if there is cancellation of positive and negative biases at different ground sites or if day to day variability is poorly simulated. To overcome the possibility of a cancellation of biases, we have analysed the statistical significance of the difference between the model and the observations at each ground site using the hourly data. Here, we include an analysis of $N_{<50}$, since the underprediction of $N_{\text {tot }}$ with the BCOC $\_l g$ and BCOC_sm experiments is largely due to an underprediction of number concentrations at the small end of the size distribution.

For this analysis, we calculated a paired $t$-test of the hourly time series of particle concentrations in the different size windows and calculated the significance at the $99 \%$ confidence level. To take into account temporal correlation in the modelled and observed time series we adjusted the $t$-statistic by calculating an "effective sample size" for each site, using the method of Wilks (1997) for second order autoregressive $(A R(2))$ data. We found the hourly time series were best fit with an AR(2) process, using a Durbin-Watson test (Durbin and Watson, 1950) to examine the residuals of the series. The $\mathrm{AR}(2)$ process best accounted for the diurnal variability and random variations visible in the observed and modelled timeseries. 


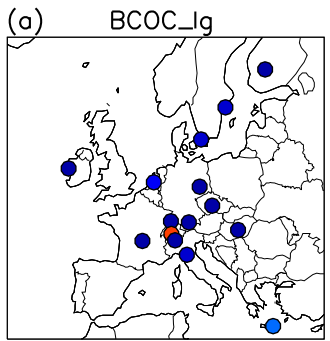

ACT-BCOC_Ig

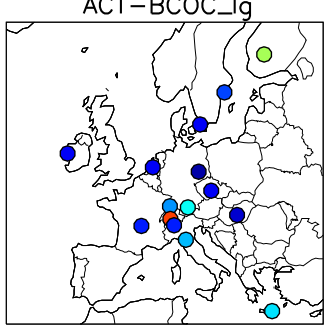

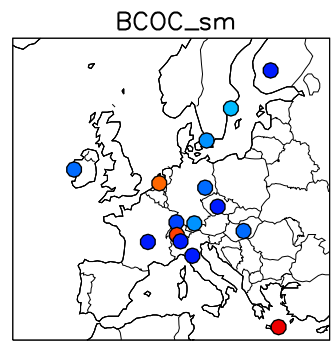

ACT-BCOC_sm

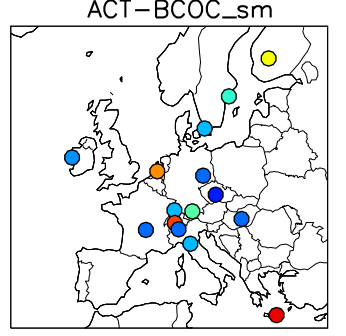

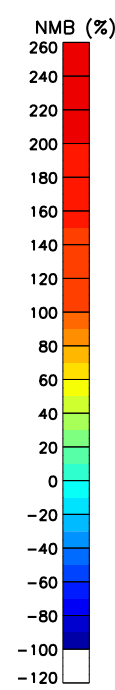

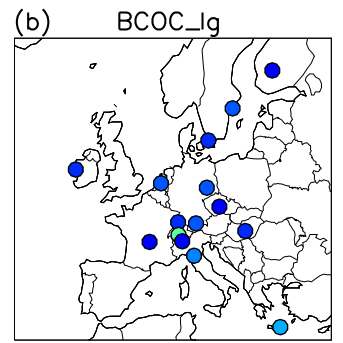

ACT-BCOC_lg

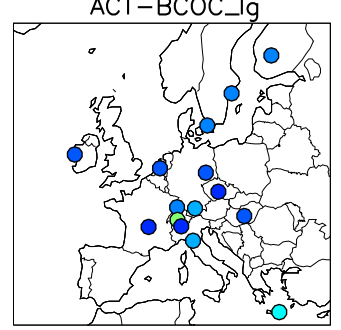

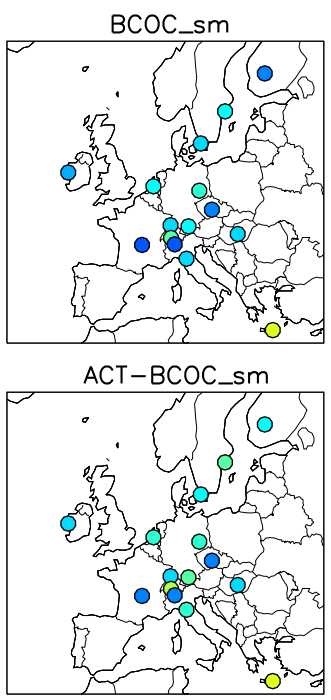

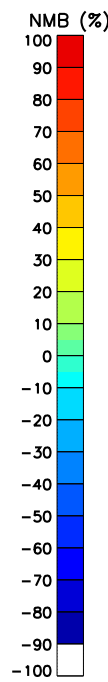

Fig. 5. Normalised mean bias (NMB) between hourly-mean modelled and observed particle number concentrations at each ground site. NMB is shown for model experiments $1-4$, Table 2 for number concentrations in the size ranges; (a) $D_{\mathrm{p}}=15-50 \mathrm{~nm}$ and (b) $D_{\mathrm{p}}>50 \mathrm{~nm}$.

In this section, we essentially test the significance of all the plausible primary aerosol experiments and BL nucleation experiments and so group the model simulations into those without BL nucleation (simulations 1-2, Table 2) and those with BL nucleation (simulations 3-10, Table 2). The range in the first set of experiments represents the uncertainty in the assumed emission size distribution for primary $\mathrm{BC}+\mathrm{OC}$ and the range in the second set of experiments represents the uncertainty in the empirical BL nucleation parameterisation used in the model. The results of the significance tests are summarised in Fig. 6.

For $N_{<50}$, we find that without BL nucleation, the modelobservation difference is statistically significant at all of the ground sites. Figure 5a shows that at 12 of the 15 sites the $\mathrm{NMB}_{\text {hourly }}$ is fairly large and negative (BCOC_lg, range -98 to $-83 \%$; BCOC_sm, range -77 to $-33 \%$ ). The exceptions are at Cabauw and Finokalia where the modelled $N_{<50}$ spans the observations (concentrations are underpredicted with BCOC_lg and overpredicted with BCOC_sm), and at the high altitude site, Jungfraujoch, where the mean $N_{<50}$ is overpredicted by a factor of $\sim 2.0$. This overprediction at Jungfraujoch was also found in our global analysis of particle number concentrations (Spracklen et al., 2010). When some form of BL nucleation is included, the model-observation difference becomes insignificant at 6 sites, showing that, statistically, nucleation is an important process affecting $N_{<50}$ at at least $40 \%$ of the ground sites.

For $N_{50}$, the model-observation difference is statistically significant at 12 of the 15 sites without BL nucleation. At the 3 sites where the model-observation difference is insignificant (Jungfraujoch, Melpitz and Cabauw), it is the BCOC_sm experiment that captures the observations. The observations at Jungfraujoch are also captured with the BCOC_lg exper- iment. At these 3 sites, the $\mathrm{NMB}_{\text {hourly }}$ is very small (range -7 to $5 \%$ ). But at the remaining 12 sites (with a significant difference) the model bias is still fairly small (Fig. 5b): for all 12 sites the bias is smallest with the BCOC_sm experiment (between $-43 \%$ and $21 \%$ ).

When some form of BL nucleation is included, the modelobservation difference in $N_{50}$ becomes insignificant at an additional 7 sites. For these sites, BL nucleation makes an important contribution to $N_{50}$. At Jungfraujoch (where the difference was insignificant with experiments BCOC_sm and $\mathrm{BCOC} \_\mathrm{lg}$ ), including BL nucleation increases the model bias, but at the $99 \%$ confidence level the model-observation difference remains statistically insignificant. Overall, with BL nucleation the difference between modelled and observed $N_{50}$ is insignificant at two thirds of the ground sites. Thus, the model with BL nucleation is in better agreement with the observations than the model without BL nucleation.

For $N_{100}$, we find that at 12 sites there is a statistically significant difference between the model and observations in experiments without $\mathrm{BL}$ nucleation. At the 3 sites where model-observation difference is statistically insignificant, again it is the BCOC_sm experiment that captures the observations. This is the same proportion of sites as for $N_{50}$, but at the sites where the difference is significant the $\mathrm{NMB}_{\text {hourly }}$ is generally smaller for $N_{100}$. For 9 sites the bias is smallest with the BCOC_sm experiment (between $-19 \%$ and $18 \%$ ), and for 2 sites the bias is smallest with the BCOC_lg experiment $(-32 \%$ at Cabauw and $9 \%$ at Finokalia). At 1 site (Jungfraujoch), there is a large negative bias with both model experiments (BCOC_sm, $-69 \%$; BCOC $l g,-81 \%)$.

When BL nucleation is included, the model-observation difference in $N_{100}$ is no longer significant at an additional 
(a) $\mathrm{N}_{<50}$

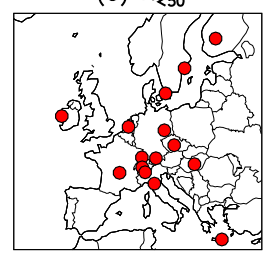

(d) $\mathrm{N}_{<50}$

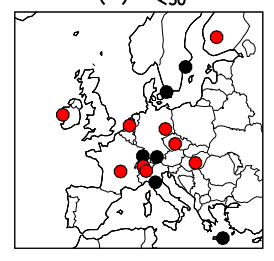

(b) $\mathrm{N}_{50}$

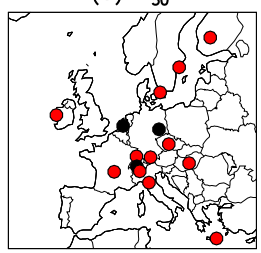

(e) $\mathrm{N}_{50}$

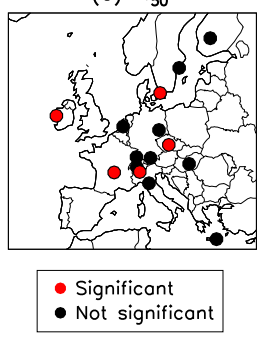

Not significant (c) $\mathrm{N}_{100}$

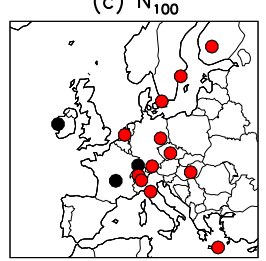

(f) $\mathrm{N}_{100}$

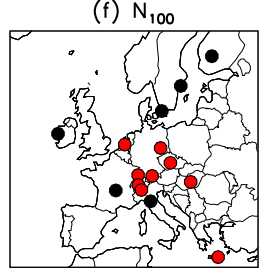

Fig. 6. Statistical significance between hourly-mean modelled and observed particle number concentrations in three size ranges; $D_{\mathrm{p}}=15-50 \mathrm{~nm} \quad\left(N_{<50}\right), \quad D_{\mathrm{p}}>50 \mathrm{~nm} \quad\left(N_{50}\right), \quad$ and $D_{\mathrm{p}}>100 \mathrm{~nm}$ $\left(N_{100}\right)$. The red dots show site locations where the difference between the model and observations is statistically significant at the $99 \%$ confidence level; the black dots show the locations where the difference is insignificant. (a), (b) and (c) show results for model experiments without BL nucleation (1-2, Table 2); (d), (e) and (f) show results for the experiments including BL nucleation (3-10, Table 2).

4 sites (Hyytiälä, Vavihill, Monte Cimone and Aspvreten). However, at 1 of the 3 sites where the difference was insignificant with experiment BCOC_sm (Schauinsland), adding BL nucleation results in an overprediction of $N_{100}$ and the model-observation difference becomes significant. In total, the model with BL nucleation is able to capture the observations at almost half of the ground sites.

We conclude from these time series comparisons that for number concentrations at the small end of the size distribution, $N_{<50}$, we need to include BL particle formation for the difference between model and observations to be statistically insignificant at roughly half of the ground sites. It is possible that a larger contribution from BL nucleation is needed in the model to capture the observations at some of the remaining sites. The observed $N_{<50}$ may also be influenced by local sources, particularly at the more polluted sites (Ispra, Cabauw and Melpitz), or by diurnal cycles in aerosol at the mountain sites Jungfraujoch (Weingartner et al., 1999) and Puy de Dôme (Venzac et al., 2009), that the model is unable to capture due to its fairly coarse resolution.

The results of the $t$-tests show that the model with BL nucleation also gives the best overall agreement with observations of $N_{50}$ and $N_{100}$, capturing the observations at two thirds and almost half the sites respectively. However, if we take into account the $\pm 10 \%$ uncertainty of the S/DMPS measurements (Wiedensohler et al., 2010), $N_{50}$ and $N_{100}$ can be explained at almost all of these sites without the need for
BL nucleation. In total, the difference between the model without BL nucleation and observations $( \pm 10 \%)$ is statistically insignificant at 8 sites for $N_{50}$ and 10 sites for $N_{100}$. Including BL nucleation in the model, the observations can be captured within $\pm 10 \%$ at an additional 4 sites for $N_{50}$ (Hyytiälä, Mace Head, Vavihill, and Schauinsland) and an additional 2 sites for $N_{100}$ (Hohenpeissenberg and Košetice). Therefore at the majority of ground sites, it is difficult to detect the contribution of BL nucleation to $N_{50}$ and $N_{100}$ within the uncertainty of the observations.

If we adjust the interval of the modelled and observed time series to better represent the average residence time of air in the model grid box $(\sim 5-20 \mathrm{~h})$, the results of the significance tests are improved but the conclusions regarding BL nucleation remain unchanged. If we compare the model to a 20-h running average of the measurements, the number of sites where the difference between modelled and observed $N_{<50}$ is statistically insignificant is increased to 12 out of 15 sites, but at all but 2 of these sites it is still necessary to include BL nucleation to capture the observations. For $N_{50}$ and $N_{100}$ the number of sites with an insignificant difference is increased to 12 and 13 sites respectively, but BL nucleation is only needed to capture the observations at $\leq 2$ of these sites. These results confirm the conclusions from the hourly time series analysis; to capture ground-based observations of $N_{<50}$ we need to include BL nucleation in the model, but for $\mathrm{CCN}$-size number concentrations only a fairly small contribution from BL nucleation (if any) is needed to capture the observations.

We recognise that $\mathrm{BL}$ nucleation may be important for $N_{<50}, N_{50}$ and $N_{100}$ at more than the number of sites discussed above, but that the observed nucleation events may not be adequately modelled for this period by the mechanisms applied in this study (Sect. 4.4). The sites at which BL nucleation is needed in the model to capture the hourly observations of $N_{<50}, N_{50}$, and $N_{100}$ are summarised in Table 4 .

\subsubsection{Analysis of particle concentration frequency distributions}

Normalised histograms of the frequency distribution of modelled and observed $N_{50}$ are shown for each site in Fig. 7. As in Gilardoni et al. (2011), we calculate the degree of overlap between the modelled and observed frequency distributions (given in Fig. 7). Figure 7 shows there is some dependence of the best-fit assumption of $\mathrm{BC}+\mathrm{OC}$ particle emission size on site location. For example, at Jungfraujoch the range of observed concentrations is captured best when larger primary $\mathrm{BC}+\mathrm{OC}$ particles are emitted, with a distribution overlap of $78 \%$. But at all other sites, the BCOC $\_l g$ experiment not only underpredicts $N_{50}$, but also underpredicts the range of concentrations observed (average overlap of $42 \%$ ). The range of observed $N_{50}$ is captured much better at most sites when 
Table 4. Summary of the ground sites at which a statistical improvement in the predicted hourly-mean number concentration is achieved by including BL nucleation in the model. The results are given for particle number concentrations in three size ranges; $D_{\mathrm{p}}=15-50 \mathrm{~nm}\left(N_{<50}\right), D_{\mathrm{p}}>50 \mathrm{~nm}\left(N_{50}\right)$, and $D_{\mathrm{p}}>100 \mathrm{~nm}\left(N_{100}\right)$. The "+" sign indicates where a statistically significant difference between the model and observations is removed by including BL nucleation. The "-" sign indicates where the reverse occurs i.e. including BL nucleation leads to a statistically significant overprediction of the observed $N_{<50}, N_{50}$, or $N_{100}$. " 0 " indicates where there is no statistically significant change in the predicted particle number concentrations with BL nucleation.

\begin{tabular}{lccc}
\hline Ground site & $N_{<50}$ & $N_{50}$ & $N_{100}$ \\
\hline Aspvreten & + & + & + \\
Cabauw & 0 & 0 & 0 \\
Finokalia & + & + & 0 \\
Hohenpeissenberg & + & + & 0 \\
Hyytiälä & 0 & + & + \\
Jungfraujoch & 0 & 0 & 0 \\
JRC-Ispra & 0 & 0 & 0 \\
K-puszta & 0 & + & 0 \\
Košetice & 0 & 0 & 0 \\
Mace Head & 0 & 0 & 0 \\
Melpitz & 0 & 0 & 0 \\
Monte Cimone & + & + & + \\
Puy de Dôme & 0 & 0 & 0 \\
Schauinsland & + & + & - \\
Vavihill & + & 0 & + \\
\hline
\end{tabular}

smaller $\mathrm{BC}+\mathrm{OC}$ particles are emitted in the model (average overlap of $67 \%$ ).

Including BL nucleation increases the range of simulated $N_{50}$ in experiment BCOC_lg and improves the agreement between modelled and observed frequency distributions (average overlap of 53-56\%, versus $42 \%$ without BL nucleation). The impact of BL nucleation is fairly small on the range of $N_{50}$ predicted by experiment BCOC_sm (average overlap of $67-68 \%$ versus $67 \%$ without BL nucleation), and at 7 sites the distribution overlap is decreased slightly. At Finokalia and Hyytiälä the distribution overlap becomes greater in experiment BCOC_lg than in BCOC_sm. However, at two thirds of the sites, the range of observed $N_{50}$ is captured best with experiment BCOC_sm (with or without BL nucleation).

In general, we find that the assumption of smaller $\mathrm{BC}+\mathrm{OC}$ particles with higher number concentration gives the best agreement with the observed frequency distribution of $N_{50}$. However, if we include BL nucleation in the model, a number of sites fit better when we assume larger emitted particles. The dependence of the best-fit model on location suggests either that the emitted primary particle size/number concentration is more variable across Europe than assumed by the constant emission size distribution prescribed in the model, or that atmospheric processes (including BL nucleation) might be influencing the shape of the size distribution in ways not represented in the model.

\subsection{Supporting aircraft observations in the boundary layer}

Figure 8 shows the mean vertical profiles of particle number concentrations measured by the DLR Falcon aircraft over the IOP in three size ranges; $4-10 \mathrm{~nm}\left(N_{4-10}\right), 10-160 \mathrm{~nm}$ $\left(N_{10-160}\right)$, and $160-1040 \mathrm{~nm}\left(N_{160-1040}\right)$. These size ranges are representative of the nucleation, Aitken, and accumulation mode size classes, respectively. Comparison with the primary aerosol model experiments (1-2, Table 2$)$ in the BL $(<2 \mathrm{~km}$ a.s.1.) is consistent with the analysis of the ground site data. There is good agreement at the larger sizes but an increasing model underprediction of particle concentrations at the small end of the size distribution. Summary statistics for $N_{4-10}, N_{10-160}$, and $N_{160-1040}$ are given in Table 5.

It is important to note that $N_{4-10}$ is a challenging quantity to compare the model with because nucleation mode particles often appear as distinct events in the aircraft data time series. Where there are no nucleation mode particles observed, measurements of $N_{4-10}$ can be negative i.e. from when measurements of $N_{10}$ are larger than $N_{4}$, indicating some uncertainty in the observations. For 3 flights, the mean $N_{4-10}$ in the BL is negative, resulting in low correlation between mean modelled and observed number concentrations in this size range $\left(R^{2} \leq 0.01\right.$ with all model simulations). For this reason, we focus mainly on the measurements at larger size $\left(N_{10-160}\right.$ and $\left.N_{160-1040}\right)$ and only show the NMB for $N_{4-10}$ in Table 5 .

Between altitudes of $\sim 2.5$ and $5 \mathrm{~km}$ the mean simulated concentrations of nucleation, Aitken, and accumulation mode particles agree reasonably well with the aircraft observations, and generally remain within $\sim 1 \sigma$ of the observations (Fig. 8). However, the model is unable to capture the peak in mean $N_{4-10}$ and $N_{10-160}$ observed in the BL.

Without BL nucleation, the model predicts very few nucleation mode particles in the BL, resulting in substantial underprediction of $N_{4-10}(\mathrm{NMB}=-100 \%)$. Including BL nucleation in experiment $\mathrm{BCOC}_{-}$lg results in a considerable decrease in the model bias with the KIN (NMB $=-38 \%)$ and ORG2 (NMB $=-33 \%)$ mechanisms. This is due to a large increase in the mean simulated $N_{4-10}$ for 3 flights, causing the model to overpredict observed BL concentrations by up to a factor of 9 for these flights, although the mean $N_{4-10}$ is still underpredicted substantially for the majority of flights with these two simulations. In the BCOC_sm experiment, the bias is only reduced slightly with BL nucleation (NMB $=-96--80 \%$, depending on the mechanism). In the vertical profile of $N_{4-10}$ (Fig. 8a), the experiments with BL nucleation due to biogenic precursors predict the highest concentrations between $\sim 4$ and $5 \mathrm{~km}$ since the ORG1 and ORG2 mechanisms are not restricted to the BL (unlike the KIN and ACT mechanisms) and can occur throughout the atmosphere 

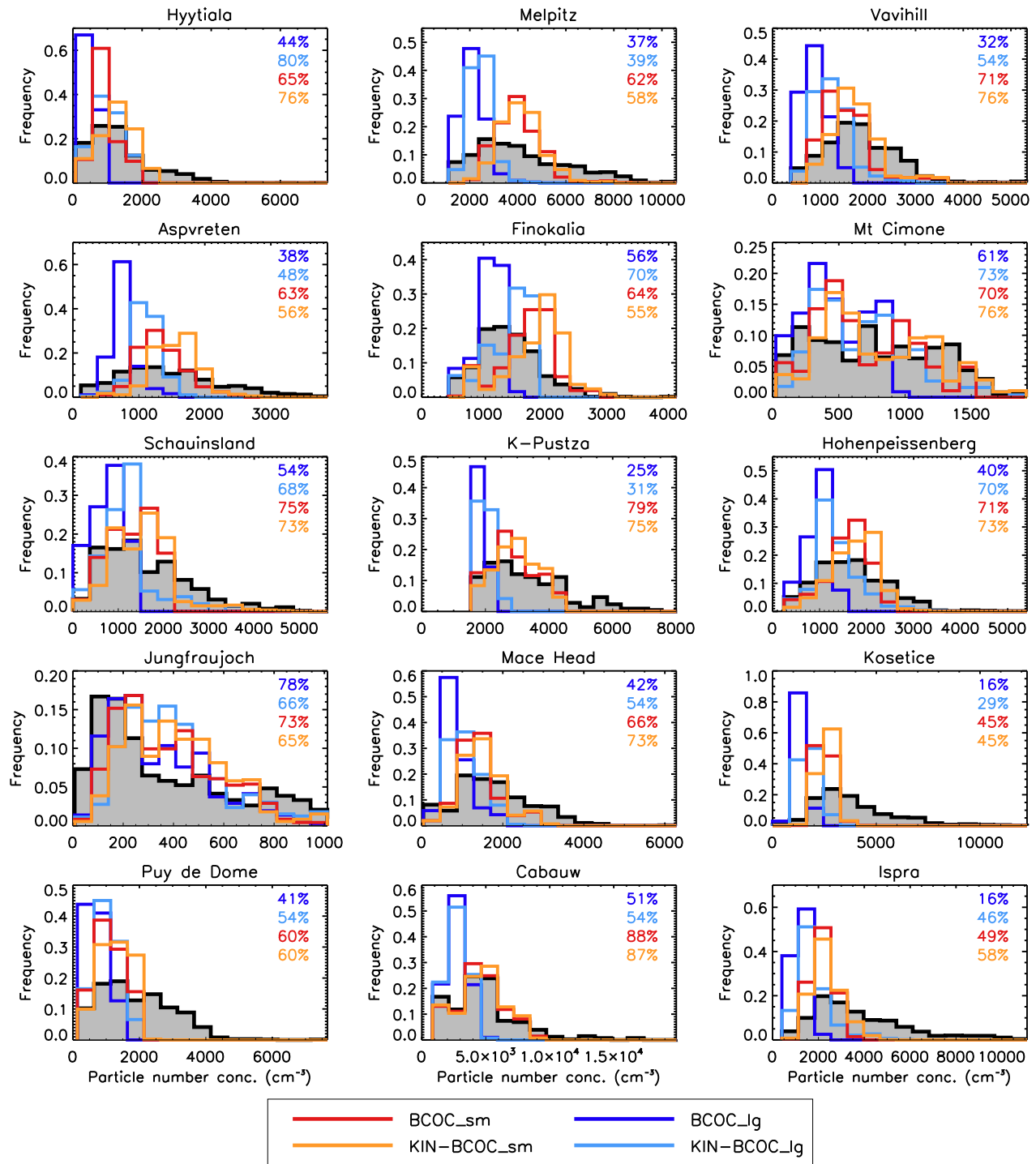

Fig. 7. Normalised histograms of the frequency distribution of hourly-mean simulated (colour) and observed (black) number concentrations of particles with $D_{\mathrm{p}}>50 \mathrm{~nm}\left(N_{50}\right)$ for May 2008 at each ground site. Bin size depends on the maximum $N_{50}$ observed at each site; number concentrations are divided into 15 equally spaced bins. The percentage overlap between the modelled and observed frequency distributions is given in the top right hand corner. Please note that the colours representing the model experiments in this figure (chosen to be easily distinguishable from each other) differ from the previous and following figures. Model experiments are described in Table 2.

providing the concentration of organic vapour is sufficiently high.

With experiment BCOC_lg the model bias is also large for $N_{10-160}(\mathrm{NMB}=-85 \%, m=0.04)$, underpredicting mean concentrations for every flight by a factor of between 2.4 and 11.9. When smaller primary particles are emitted (BCOC_sm) the bias in $N_{10-160}$ is reduced (NMB $=-63 \%$, $m=0.17)$, but mean concentrations are still underpredicted for every flight by a factor of between 1.4 and 4.9. The spatial distribution of $N_{10-160}$ is also improved by emitting smaller BC+OC particles (BCOC_lg, $R^{2}=0.04$; BCOC_sm, $R^{2}=0.21$ ). Including BL nucleation reduces the bias further to $-59--44 \%$ (depending on the mechanism and on the $\mathrm{BC}+\mathrm{OC}$ emission size). However, the smaller NMB is mainly due to a large increase in modelled concentrations and overprediction for 1 flight (NMB with this flight removed is also shown in Table 5). As a result, the spatial distribution of $N_{10-160}$ is not as well captured with BL nucleation $\left(R^{2}<0.03\right)$.

The whole vertical profile of $N_{160-1040}$ is captured fairly well by the model, with a peak in concentration in the BL that rapidly decreases above an altitude of $\sim 2.5 \mathrm{~km}$ (Fig. 8c). The model without BL nucleation slightly underestimates the mean $N_{160-1040}$ observed in the BL (BCOC_sm, $\mathrm{NMB}=-22 \%, m=0.31 ; \mathrm{BCOC} \_l g, \mathrm{NMB}=-21 \%, m=$ 0.34). Although this particle size-range is generally 

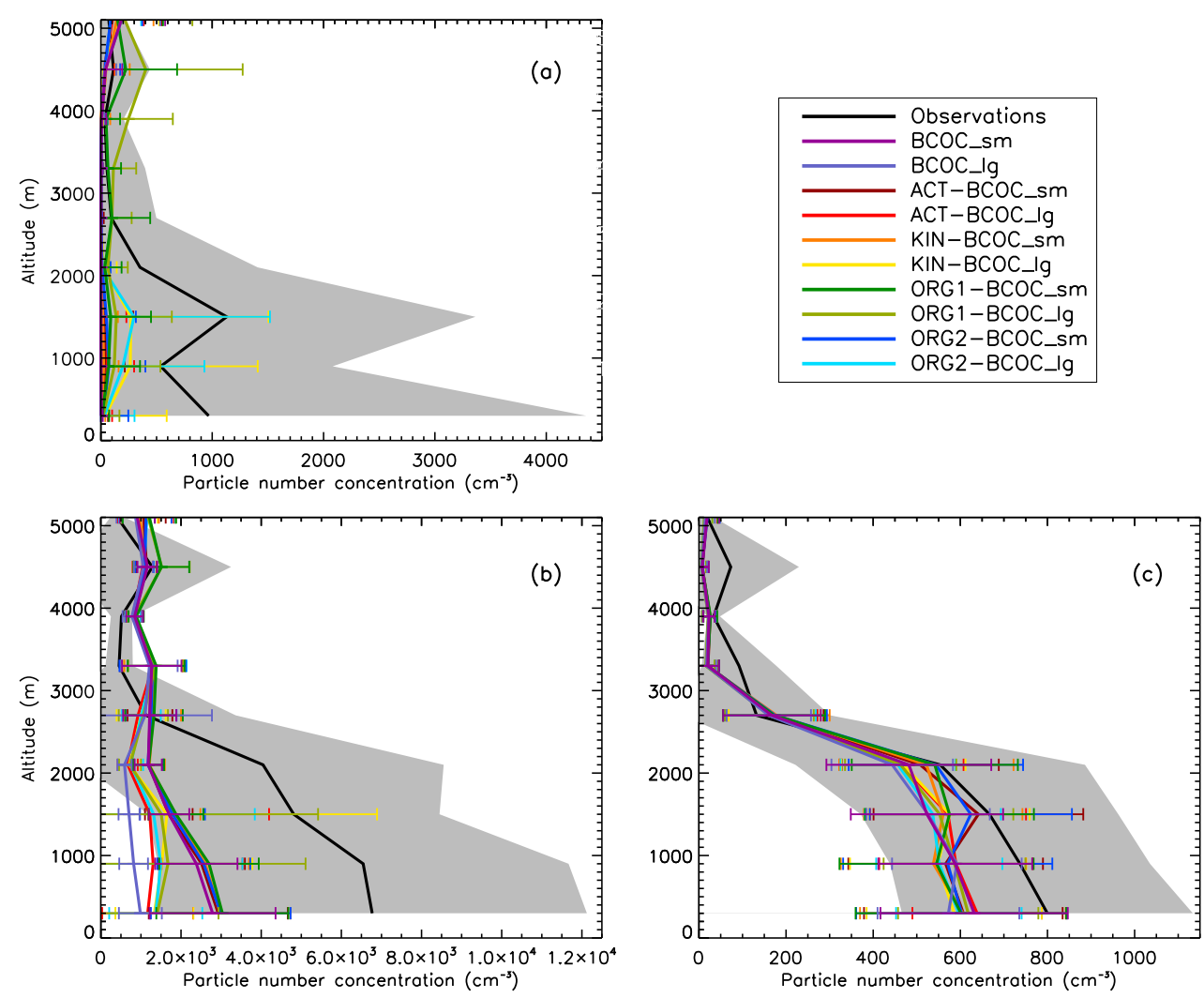

Fig. 8. Vertical profiles of observed (black) and modelled (colour) particle number concentrations in the diameter ranges: (a) 4-10 nm, (b) 10-160 nm, and (c) 160-1040 nm. Observations are from the DLR Falcon 20 aircraft. The average over all measurement flights performed during the LONGREX campaign (May 2008) is shown (sectioned into $600 \mathrm{~m}$ altitude bins). The error bars and shading represent the standard deviation of the model and observations, respectively. Model experiments listed in the legend are described in Table 2.

dominated by secondary aerosol mass, the number concentrations may well be explained by primary emissions (and some contribution from BHN) because the condensation of secondary aerosol species onto primary particle cores occurs without a change in number concentration. Particle growth via condensation of $\mathrm{H}_{2} \mathrm{SO}_{4}$ and $\mathrm{SOA}$ is included in all model experiments. There is also likely to be some contribution to growth from condensation of ammonium nitrate (not included in the model) towards the top of the BL (Morgan et al., 2010, see Sect. 3.3), which may explain some of the model underprediction of $N_{160-1040}$.

The impact of BL nucleation on number concentrations at the large end of the size distribution is relatively small, with an average change in the mean simulated $N_{160-1040}$ for each flight of $\sim 2 \%$. But in the BCOC_lg experiment, the overall agreement between mean modelled and observed $N_{160-1040}$ is generally improved with BL nucleation. This can be interpreted as a decreasing influence of primary emissions aloft in the BL compared with observations at the surface. For number concentrations in this size range the $\mathrm{BCOC} \_\mathrm{lg}$ experiment gives slightly better agreement with the aircraft observations which is consistent with comparisons with the ground-based observations.

\subsection{Supporting observations of non-volatile particles}

Further information on the number concentrations of carbonaceous particles can be obtained from measurements of non-volatile cores. Here, we use the measurements of nonvolatile particle size and number concentration made onboard the DLR Falcon aircraft. Previous studies using measurements of non-volatile particles have found that the submicron non-volatile fraction essentially consists of primary BC (soot) particles from combustion sources with some contribution from organic compounds (Rose et al., 2006; Engler et al., 2007; Birmili et al., 2009). Most of the volatile aerosol species such as sulphate, nitrate, ammonium and some volatile organic compounds are evaporated at temperatures below $250^{\circ} \mathrm{C}$. Other non-volatile aerosol species such as inorganic salts and crustal material are likely to contribute mainly to measured non-volatile number concentrations in the super-micron size range (Rose et al., 2006; Birmili et al., 2009). We therefore assume that the observed submicron non-volatile particles can be compared with the simulated $\mathrm{BC}+\mathrm{OC}$ particle number concentration from the model.

Figure 9 shows a mean campaign vertical profile of observed non-volatile particle number concentration 
Table 5. Summary statistics for particle number concentrations in the diameter ranges; $4-10 \mathrm{~nm}\left(N_{4-10}\right), 10-160 \mathrm{~nm}\left(N_{10-160}\right)$, and $160-$ $1040 \mathrm{~nm}\left(N_{160-1040}\right)$. The normalised mean bias (NMB), slope of the linear regression $(m)$ and correlation coefficient $\left(R^{2}\right)$ are calculated between the simulated and observed mean number concentrations in the BL $(\leq 2000 \mathrm{~m}$ a.s.l.) for each flight performed by the DLR Falcon aircraft during LONGREX, May 2008. $R^{2}$ and $m$ are not given for $N_{4-10}$ for reasons explained in Sect. 4.2. Values in brackets are statistics calculated with 1 flight (the second flight on 22 May) removed.

\begin{tabular}{lccccccc}
\hline Model & \multicolumn{3}{c}{ NMB $(\%)$} & \multicolumn{2}{c}{$m$} & \multicolumn{2}{c}{$R^{2}$} \\
Experiment & $N_{4-10}$ & $N_{10-160}$ & $N_{160-1040}$ & $N_{10-160}$ & $N_{160-1040}$ & $N_{10-160}$ & $N_{160-1040}$ \\
\hline BCOC_lg & -100 & -85 & -21 & 0.04 & 0.34 & 0.04 & 0.26 \\
BCOC_sm & -100 & -63 & -22 & 0.17 & 0.31 & 0.21 & 0.14 \\
ACT-BCOC_lg & -92 & $-59(-83)$ & -19 & $-0.40(0.02)$ & 0.57 & 0.03 & 0.49 \\
ACT-BCOC_sm & -95 & $-59(-61)$ & -17 & $0.06(0.08)$ & 0.26 & 0.02 & 0.07 \\
KIN-BCOC_lg & -38 & $-44(-80)$ & -21 & $-0.64(0.01)$ & 0.27 & 0.03 & 0.11 \\
KIN-BCOC_sm & -96 & $-56(-60)$ & -22 & $0.06(0.08)$ & 0.25 & 0.02 & 0.08 \\
ORG1-BCOC_lg & -71 & $-47(-79)$ & -20 & $-0.58(0.01)$ & 0.51 & 0.03 & 0.41 \\
ORG1-BCOC_sm & -80 & $-54(-59)$ & -22 & $<0.03(0.08)$ & 0.22 & $<0.01$ & 0.06 \\
ORG2-BCOC_lg & -33 & $-59(-79)$ & -24 & $-0.35(0.02)$ & 0.40 & 0.03 & 0.32 \\
ORG2-BCOC_sm & -90 & $-56(-61)$ & -17 & $0.01(0.06)$ & 0.16 & $<0.01$ & 0.02 \\
\hline
\end{tabular}

$\left(D_{\mathrm{p}}>14 \mathrm{~nm}\right)$ measured using a thermodenuder and CPC, compared with the modelled number concentration of $\mathrm{BC}+\mathrm{OC}$ particles $\left(D_{\mathrm{p}}>14 \mathrm{~nm}\right)$. The highest non-volatile particle concentrations were observed in the BL as a result of surface primary emissions. The model captures the general shape of the observed vertical profile with maximum number concentrations in the BL decreasing with increasing altitude.

Figure 9 shows how the size of emitted $\mathrm{BC}+\mathrm{OC}$ particles affects the number concentration for fixed mass (simulations 1-2, Table 2). On average, there is a factor $\sim 3.8$ change in total simulated $\mathrm{BC}+\mathrm{OC}$ particle number concentration $\left(D_{\mathrm{p}}>3 \mathrm{~nm}\right)$ in the European BL between experiments BCOC_lg and BCOC_sm. We note that this ratio is not the same as the ratio of emitted number concentrations (which is a factor of $\sim 4.4$ for FF emissions) due to non-linear effects of microphysical and removal processes on particle concentrations.

The model underpredicts the mean non-volatile particle concentrations in the BL for every flight by a factor of 2.510.4 (NMB $=-78 \%$ ), when we assume emission of large $\mathrm{BC}+\mathrm{OC}$ particles (BCOC_lg). Emitting smaller $\mathrm{BC}+\mathrm{OC}$ particles (BCOC_sm) reduces the bias $(\mathrm{NMB}=-32 \%$ ) and mean concentrations are predicted within a factor of 2.8. To achieve good agreement with the observations (NMB $=-3 \%$ ) we need to further reduce the assumed emission size of carbonaceous aerosol in the model by a factor of $\sim 1.2$ (experiment "BCOC_vsm" in Fig. 9), which increases the total simulated $\mathrm{BC}+\mathrm{OC}$ number concentration over $\mathrm{Eu}$ rope by a factor of $\sim 1.5$ relative to $\mathrm{BCOC}_{-}$sm.

The model underprediction of the BL non-volatile particle number concentration is largest in the $\mathrm{BCOC}_{-} \lg$ experiment, in which the emitted $\mathrm{BC}+\mathrm{OC}$ size distribution is more in-line with measured BC emission sizes in the literature (Sect. 3.2). Only by increasing the emitted number concentration of carbonaceous aerosol in BCOC_lg by more than a factor of $\sim 6$ (in experiment BCOC_vsm) are we able to capture the observations, which suggests that (i) the removal of $\mathrm{BC}+\mathrm{OC}$ particles is too efficient in the model, (ii) the non-volatile counter is not measuring the same particles as assumed in the model, or (iii) the model is missing a large contribution of non-volatile particles. Concerning (i): if we substantially reduce the in-cloud nucleation scavenging efficiency in the model (by decreasing the fraction of condensate that is converted to dynamic rain in $6 \mathrm{~h}$ by a factor of 10$)$, the campaign-mean $\mathrm{BC}+\mathrm{OC}$ number concentration $\left(D_{\mathrm{p}}>14 \mathrm{~nm}\right)$ is increased by only $\sim 20 \%$ in the BL. Concerning (ii): it is possible that pyrolysis of volatile $\mathrm{OC}$ in the thermodenuder might produce a residual core (a few nanometers in diameter) which appears as a non-volatile particle. If the residuals produced by this process are larger than $14 \mathrm{~nm}$ they would be counted by the CPC, resulting in an overestimation of the ambient non-volatile particle number concentration.

Concerning (iii) (and (ii)): in experiments BCOC_sm and lg it is possible that we are neglecting some contribution from residuals of partly volatile species, detected as a nonvolatile size mode with $D_{\mathrm{p}}<20 \mathrm{~nm}$ in an urban environment (Birmili et al., 2010) and in the rural background (Engler et al., 2007); the composition of which is unknown. Birmili et al. (2010) suggest the non-volatile residuals originate from particles containing a high volume fraction of volatile species ( $90 \%$ ), such as organic compounds from both direct vehicle emission and secondary formation processes. Secondary particles with $D_{\mathrm{p}}<20 \mathrm{~nm}$ have also been observed to contain non-volatile residuals at rural sites (Wehner et al., 2005; Ehn et al., 2007). In the model we treat all secondary (nucleated) particles as volatile. It is unclear whether these residuals make an important contribution to the non-volatile particle number concentrations observed aloft in the BL, but they could explain some of the model discrepancy. 


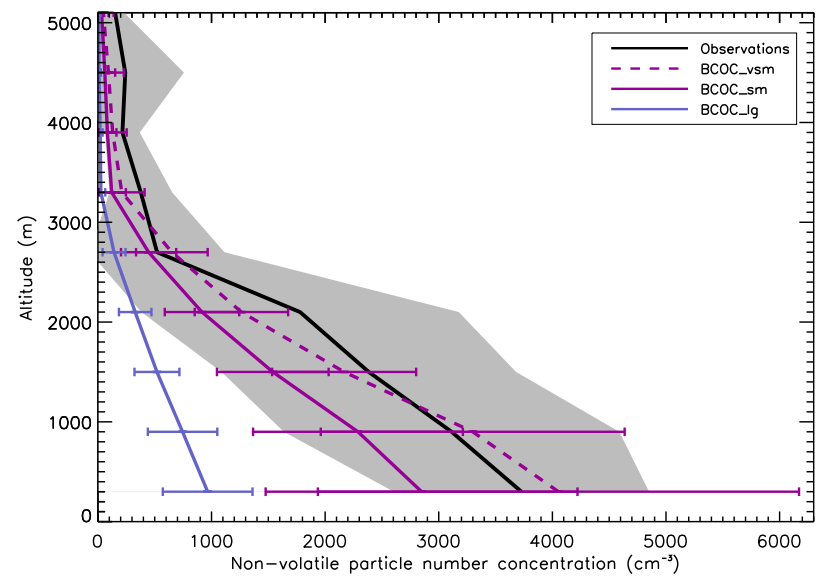

Fig. 9. Vertical profile of measured non-volatile particle number concentration $\left(D_{\mathrm{p}}>14 \mathrm{~nm}\right)$ from the DLR Falcon 20 aircraft (black) compared with modelled number concentration of $\mathrm{BC}+\mathrm{OC}$ particles $\left(D_{\mathrm{p}}>14 \mathrm{~nm}\right)$ (colour). The average over all measurement flights performed during the LONGREX campaign (May 2008) is shown (sectioned into $600 \mathrm{~m}$ altitude bins). The error bars and shading represent the standard deviation of the model and observations respectively. Model experiments, BCOC_sm and BCOC_lg, are described in Table 2. In the BCOC_vsm experiment, the peak diameter of the $\mathrm{BC}+\mathrm{OC}$ emission size distribution in $\mathrm{BCOC}_{-}$sm is reduced by a factor of $\sim 1.2$.

Assuming a very small initial size for primary $\mathrm{BC}+\mathrm{OC}$ particles (experiment BCOC_vsm) increases the modelled non-volatile particle number concentration, compensating for non-volatile residuals that may be neglected by the simple representation of non-volatile particles in our model. However, we believe a diameter of $25 \mathrm{~nm}$ assumed for $D_{\mathrm{FF}}$ in experiment BCOC_vsm, is unrealistically small for directly emitted BC particles from traffic sources and (taking into account sub-grid scale processing) this diameter may also be too small for the mean $\mathrm{BC}+\mathrm{OC}$ particle size over a large model grid box (Sect. 3.2).

We also compare the model with the non-volatile number size distribution in the dry diameter range $\sim 0.265-2.25 \mu \mathrm{m}$ measured by the OPC instrument. Seven hours of measurements were selected (from 6 different flights), where the hourly-mean altitude of the aircraft was lower than $2 \mathrm{~km}$ a.s.l. Figure 10 shows the simulated number size distribution of $\mathrm{BC}+\mathrm{OC}$ particles compared with the observed non-volatile particle number size distribution in the BL. We assume the evaporation of all volatile species occurs before measurement, so that the observed size distribution in Fig. 10 shows the size distribution of non-volatile particle cores. We try to replicate this in the model by calculating the size distribution of the BC particle "cores". Sulphate and SOA that have accumulated on the $\mathrm{BC}+\mathrm{OC}$ particles in distribution 1 during the ageing process act to increase the particle size (Sect. 3.4). We remove this effect by calculating the size of the $\mathrm{BC}$ particles from the mass of $\mathrm{BC}$ and the $\mathrm{BC}+\mathrm{OC}$ particle number con-

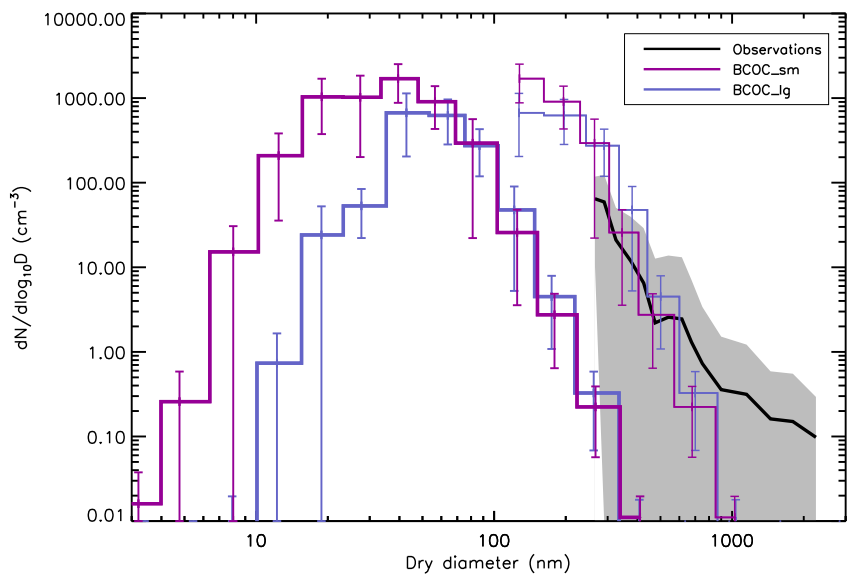

Fig. 10. Mean number size distributions of measured non-volatile particles (black) and of modelled carbonaceous particles (colour) for all flight hours with a mean altitude less than $2 \mathrm{~km}$ a.s.l. The total modelled size distribution of BC particle cores is shown in bold and the modelled size distribution of aged $\mathrm{BC}+\mathrm{OC}$ (with condensed $\mathrm{SO}_{4}$ and SOA) is shown for sizes larger than $\sim 100 \mathrm{~nm}$. The error bars and shading represent the standard deviation of the model and observations, respectively. Model experiments, BCOC_lg and BCOC_sm, are described in Table 2.

centration (assuming a density of $1.8 \mathrm{gcm}^{-3}$ ). Figure 10 also shows the modelled size distribution of all components in distribution 1; a mixture of fresh and aged carbonaceous particles $\left(\mathrm{SO}_{4} / \mathrm{BC} / \mathrm{OC}\right)$. The modelled size distribution of $\mathrm{BC}$ particle cores is shifted to smaller sizes compared with the modelled distribution of aged $\mathrm{BC}+\mathrm{OC}$ particles.

The observed mean non-volatile particle number size distribution is underpredicted by the modelled "BC-only" size distribution, but the agreement between the modelled distribution of aged $\mathrm{BC}+\mathrm{OC}$ particles and the observations is reasonably good (Fig. 10). If we compare the modelled and observed non-volatile particle number concentrations in the submicron size range (between $\sim 0.265$ and $\sim 1 \mu \mathrm{m}$ ), the difference between the integrated flight-mean modelled aged $\mathrm{BC}+\mathrm{OC}$ particle distribution and the observations is statistically insignificant at the $95 \%$ confidence level. The difference between the submicron modelled BC-only size distribution and the observations, on the other hand, is statistically significant. These results suggest that the measured non-volatile particle size distribution does not only consist of $\mathrm{BC}$, but is likely to include contributions from non-volatile organic matter. In addition, sea salt particles (Jennings and O'Dowd, 1990; O'Dowd and Smith, 1993) and mineral dust may contribute to the measured non-volatile particle number concentrations, which are not included in the modelled size distribution in Fig. 10. However, these species are only likely to make substantial contributions in the super-micron size range. At these large sizes the differences between model experiments BCOC_lg and BCOC_sm are relatively small. 

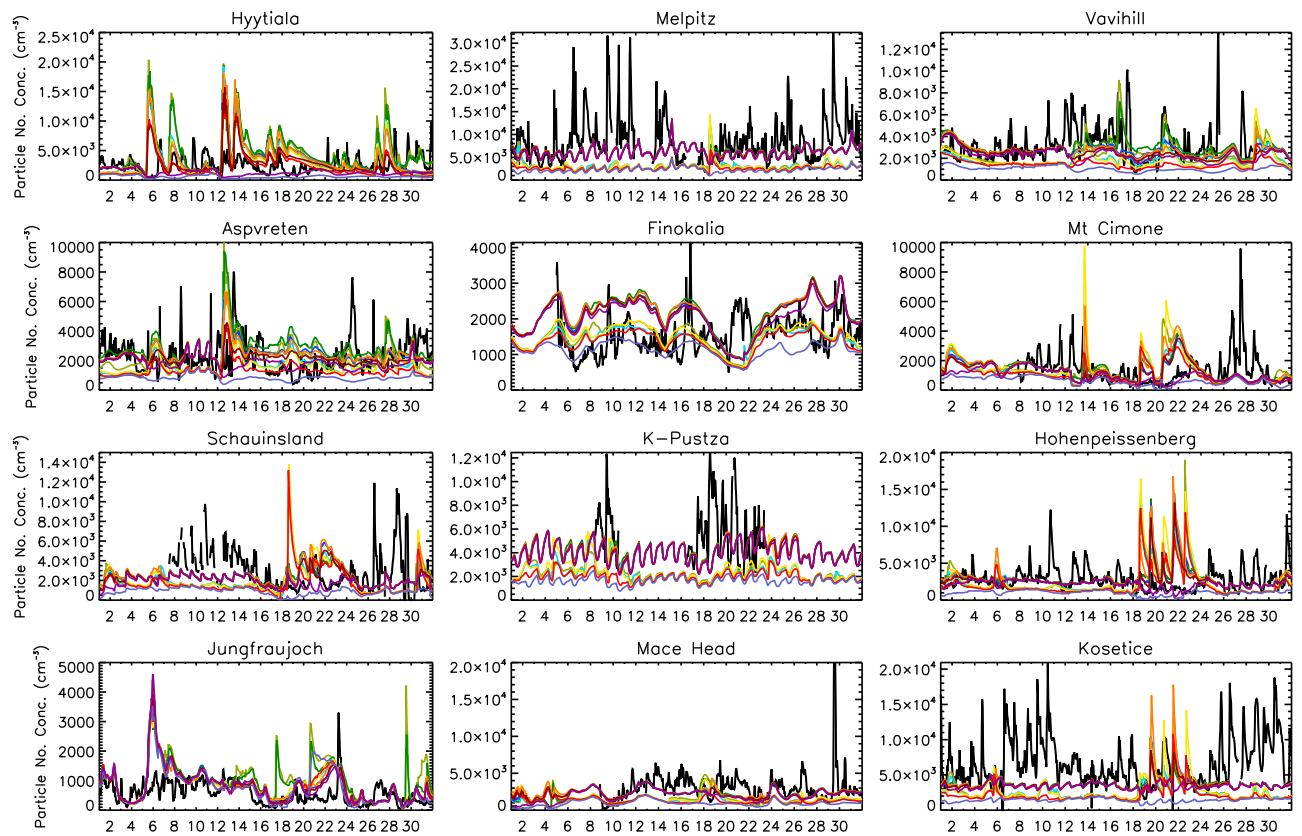

Moce Head
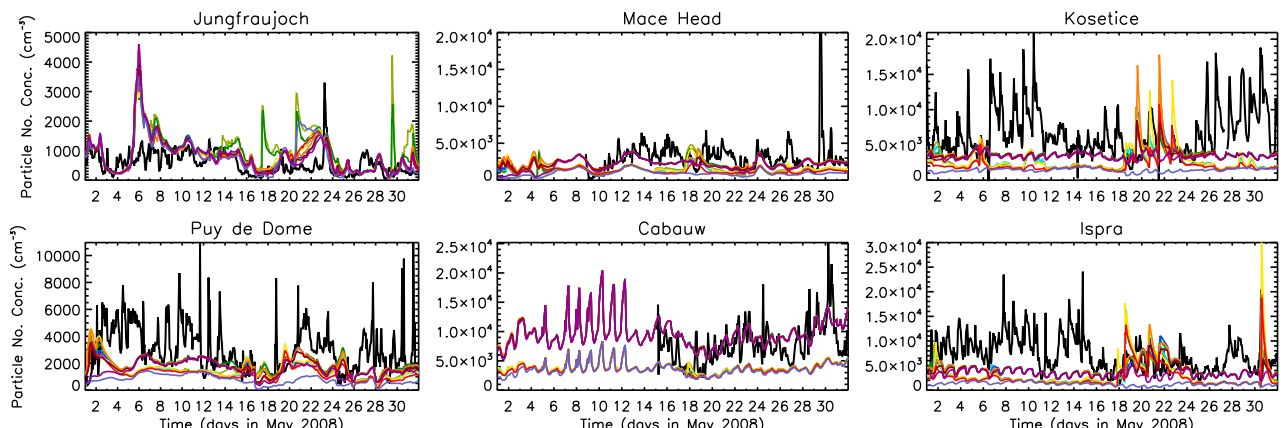

Cabouw

Ispra
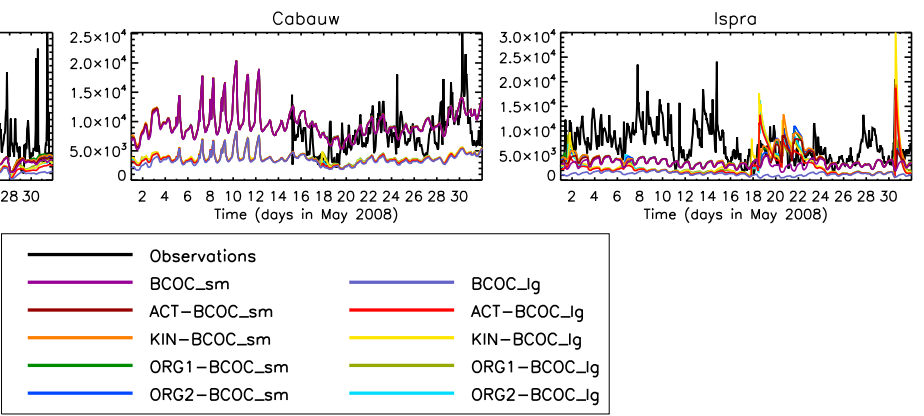

Fig. 11. May 2008 time-series of hourly-mean modelled (colour) and observed (black) particle number concentrations $\left(D_{\mathrm{p}}>15 \mathrm{~nm}\right)$ at each ground site. Model experiments listed in the legend are described in Table 2.

\subsection{Time series of particle number concentrations}

Conclusions regarding the best nucleation mechanism are hard to draw because of the difficulty in detecting a statistically significant impact of BL nucleation on $\mathrm{CCN}$-sized particle number concentrations within the uncertainty in the ground based observations (Sect. 4.1.2). In addition, the predicted time series of $N_{\text {tot }}$ has a temporal pattern that is in poor agreement with the observations (Fig. 11). The correlation between modelled and observed hourly-mean $N_{\text {tot }}$ and $N_{100}$ at each site are given in Table 6 . Without BL nucleation, the correlation between hourly-mean modelled and observed $N_{\text {tot }}$ is fairly low at most of the sites (average $R_{\text {hourly }}^{2}=0.08$ ), but is reduced further when BL nucleation is included (average $R_{\text {hourly }}^{2}=0.05$ ). The exception is at Cabauw where the correlation between model and observations is fairly good with all simulations (average $R_{\text {hourly }}^{2}=0.28$ ). The poor model skill is reflected in the $R^{2}$ values in Table 3: the correlation between modelled and observed campaign-mean $N_{\text {tot }}$ is generally reduced when BL nucleation is included.
Increasing the 1-h interval of the time series to $20 \mathrm{~h}$ (an estimate of the average residence time of air in the model grid box), marginally improves the correlation between modelled and observed $N_{\text {tot }}$ (average $R_{\text {hourly }}^{2}=0.17$ without BL nucleation; average $R_{\text {hourly }}^{2}=0.10$ with BL nucleation). The temporal correlation between the model with BL nucleation and observations remains lower than the model without BL nucleation, suggesting possible errors present in the modelling of BL nucleation events for this period.

Periodic features visible in the simulated time series of $N_{\text {tot }}$ at some of the sites (Fig. 11) result from the development of the model BL. These features are most prominent during Period A at the relatively low level, Central European sites Melpitz, K-pustza, Ispra, and Cabauw, where the influence of BL nucleation on modelled $N_{\text {tot }}$ is relatively small. At night-time the model BL becomes shallower and stably-stratified increasing particle number concentrations at the surface, which decrease through the day-time (in the absence of BL nucleation) as the model BL height increases. 
Table 6. Correlation coefficient $\left(R^{2}\right)$ between observed and simulated hourly mean particle number concentrations (a) $D_{\mathrm{p}}>15 \mathrm{~nm}$ and (b) $D_{\mathrm{p}}>100 \mathrm{~nm}$ at each ground site. Ground site acronyms are given in Table 1.

\begin{tabular}{|c|c|c|c|c|c|c|c|c|c|c|c|c|c|c|c|}
\hline $\begin{array}{l}\text { (a) Model } \\
\text { experiment }\end{array}$ & ASP & CBW & FKL & HPB & HTL & JFJ & JRC & KPO & KTC & MHD & MPZ & MTC & PDD & SLD & VHL \\
\hline BCOC_hi & $<0.01$ & 0.30 & 0.05 & 0.13 & 0.01 & 0.16 & 0.09 & 0.09 & 0.02 & 0.04 & $<0.01$ & 0.15 & 0.17 & 0.16 & $<0.01$ \\
\hline BCOC_lo & $<0.01$ & 0.27 & 0.02 & 0.16 & $<0.01$ & 0.20 & 0.03 & 0.08 & $<0.01$ & 0.05 & 0.01 & 0.09 & 0.12 & 0.09 & 0.01 \\
\hline ACT-BCOC_hi & $<0.01$ & 0.31 & 0.02 & 0.09 & $<0.01$ & 0.19 & 0.01 & 0.09 & 0.07 & $<0.01$ & 0.03 & 0.02 & 0.01 & 0.05 & $<0.01$ \\
\hline ACT-BCOC_lo & 0.01 & 0.27 & 0.02 & 0.02 & $<0.01$ & 0.21 & 0.01 & 0.08 & 0.04 & 0.03 & 0.01 & $<0.01$ & 0.06 & $<0.01$ & $<0.01$ \\
\hline KIN-BCOC_hi & $<0.01$ & 0.26 & 0.01 & 0.09 & $<0.01$ & 0.17 & 0.01 & 0.02 & 0.03 & $<0.01$ & 0.02 & 0.02 & $<0.01$ & 0.05 & 0.01 \\
\hline KIN-BCOC_lo & $<0.01$ & 0.27 & 0.01 & 0.04 & $<0.01$ & 0.18 & 0.01 & 0.08 & 0.04 & 0.01 & 0.01 & 0.01 & 0.02 & 0.01 & $<0.01$ \\
\hline ORG1-BCOC_hi & 0.01 & 0.22 & 0.01 & 0.09 & $<0.01$ & 0.06 & $<0.01$ & 0.03 & 0.05 & 0.01 & 0.02 & 0.04 & $<0.01$ & 0.07 & 0.06 \\
\hline ORG1-BCOC_lo & 0.01 & 0.27 & 0.01 & 0.03 & $<0.01$ & 0.10 & $<0.01$ & 0.10 & 0.09 & 0.03 & 0.03 & $<0.01$ & 0.02 & 0.01 & 0.02 \\
\hline ORG2-BCOC_hi & $<0.01$ & 0.30 & 0.02 & 0.09 & $<0.01$ & 0.19 & 0.01 & 0.01 & 0.03 & $<0.01$ & 0.01 & 0.02 & $<0.01$ & 0.06 & 0.05 \\
\hline ORG2-BCOC_lo & $<0.01$ & 0.27 & 0.02 & 0.02 & 0.01 & 0.22 & 0.01 & 0.08 & 0.05 & 0.03 & 0.01 & $<0.01$ & 0.04 & 0.01 & 0.01 \\
\hline $\begin{array}{l}\text { (b) Model } \\
\text { experiment }\end{array}$ & ASP & CBW & FKL & HPB & HTL & $\mathrm{JFJ}$ & JRC & KPO & KTC & MHD & MPZ & MTC & PDD & SLD & VHL \\
\hline BCOC_hi & 0.12 & 0.62 & 0.04 & 0.33 & 0.47 & 0.05 & 0.45 & $<0.01$ & 0.19 & 0.34 & 0.17 & 0.34 & 0.30 & 0.22 & 0.32 \\
\hline BCOC_lo & 0.13 & 0.48 & 0.02 & 0.37 & 0.43 & 0.08 & 0.42 & $<0.01$ & 0.10 & 0.29 & 0.07 & 0.35 & 0.24 & 0.24 & 0.24 \\
\hline ACT-BCOC_hi & 0.05 & 0.63 & 0.01 & 0.30 & 0.40 & 0.05 & 0.37 & $<0.01$ & 0.18 & 0.31 & 0.20 & 0.33 & 0.30 & 0.20 & 0.30 \\
\hline ACT-BCOC_lo & 0.09 & 0.47 & 0.02 & 0.35 & 0.42 & 0.07 & 0.41 & $<0.01$ & 0.11 & 0.28 & 0.10 & 0.35 & 0.24 & 0.25 & 0.25 \\
\hline KIN-BCOC_hi & 0.08 & 0.63 & $<0.01$ & 0.30 & 0.42 & 0.05 & 0.35 & $<0.01$ & 0.18 & 0.29 & 0.19 & 0.32 & 0.27 & 0.19 & 0.26 \\
\hline KIN-BCOC_lo & 0.10 & 0.49 & 0.01 & 0.33 & 0.43 & 0.09 & 0.40 & $<0.01$ & 0.11 & 0.27 & 0.07 & 0.34 & 0.23 & 0.25 & 0.24 \\
\hline ORG1-BCOC_hi & 0.09 & 0.61 & 0.01 & 0.29 & 0.38 & 0.05 & 0.33 & 0.01 & 0.16 & 0.27 & 0.17 & 0.32 & 0.27 & 0.20 & 0.23 \\
\hline ORG1-BCOC_lo & 0.12 & 0.49 & 0.01 & 0.34 & 0.45 & 0.08 & 0.37 & 0.01 & 0.09 & 0.27 & 0.09 & 0.34 & 0.26 & 0.26 & 0.25 \\
\hline ORG2-BCOC_hi & 0.06 & 0.61 & 0.02 & 0.30 & 0.41 & 0.05 & 0.34 & $<0.01$ & 0.18 & 0.30 & 0.18 & 0.32 & 0.27 & 0.20 & 0.28 \\
\hline ORG2-BCOC_lo & 0.10 & 0.48 & 0.02 & 0.33 & 0.44 & 0.06 & 0.41 & $<0.01$ & 0.11 & 0.27 & 0.07 & 0.35 & 0.25 & 0.26 & 0.26 \\
\hline
\end{tabular}

Analysis of modelled and observed condensation sink (CS; Eq. 7) at all sites suggests that the nucleation sink term is not the cause of the poor agreement (Fig. 12). The statistical values for CS with all model experiments $\left(\mathrm{NMB}=-29-6 \%, m=0.53-0.69, R^{2}=0.73-0.74\right.$, average $R_{\text {hourly }}^{2}=0.25$ ) are considerably better than for $N_{\text {tot }}$. A more likely reason for the poor prediction of nucleation events is sulphuric acid. Figure 13 compares the simulated time series of gas-phase sulphuric acid concentrations with chemical ionization mass spectrometer (e.g. Berresheim et al., 2000) measurements at Melpitz.

All model simulations underpredict the high concentrations of sulphuric acid observed at Melpitz during Period A by a factor of 1.7-4.6. Lower concentrations observed between $\sim 18-24$ May are likely to have contributed to the decrease in $N_{\text {tot }}$ during Period B (Fig. 11), despite the reduction in observed CS. In contrast, the modelled concentrations of sulphuric acid increase in Period B at Melpitz and at the majority of ground sites, driving the increase in nucleation events predicted by the model. One explanation for the relatively poor agreement is that processes that drive dayto-day changes and hourly variability in gas-phase sulphuric acid concentrations are unaccounted for in the model. In particular, we neglect the impact of cloud cover on incoming radiation and $\mathrm{OH}$ concentrations. If the dynamic of the diurnal cycles of sulphuric acid concentrations is wrong in the model then this can result in too small nucleation rates at the surface.
The simplified SOA formation scheme used in the model may also be responsible for the relatively poor correlation between modelled and measured hourly means. In particular, the scheme does not include contributions from anthropogenic volatile or intermediate-volatile organic compounds, which may have large implications for the growth rate and survival of the particles formed by BL nucleation. We recognise that more attention to modelling gas-phase $\mathrm{H}_{2} \mathrm{SO}_{4}$ and SOA formation is needed in future studies.

\section{Summary and conclusions}

We have evaluated the global aerosol microphysics model, GLOMAP against extensive measurements of total particle number concentration and size distribution made during the EUCAARI May 2008 campaign. We have focused on aerosol concentrations in the European boundary layer (BL), using surface-based measurements from 15 EUSAAR and GUAN ground sites with airborne measurements from the DLR Falcon 20 aircraft.

The aim of this study was to better understand how primary particle emissions and secondary particle formation in the BL influence total particle number concentrations over Europe, and how the influence varies across the particle size distribution (nucleation, Aitken and accumulation mode sizes). We have extended the monthly-mean analysis of total particle concentrations in Spracklen et al. (2010) to include aerosol measurements from different platforms, higher 

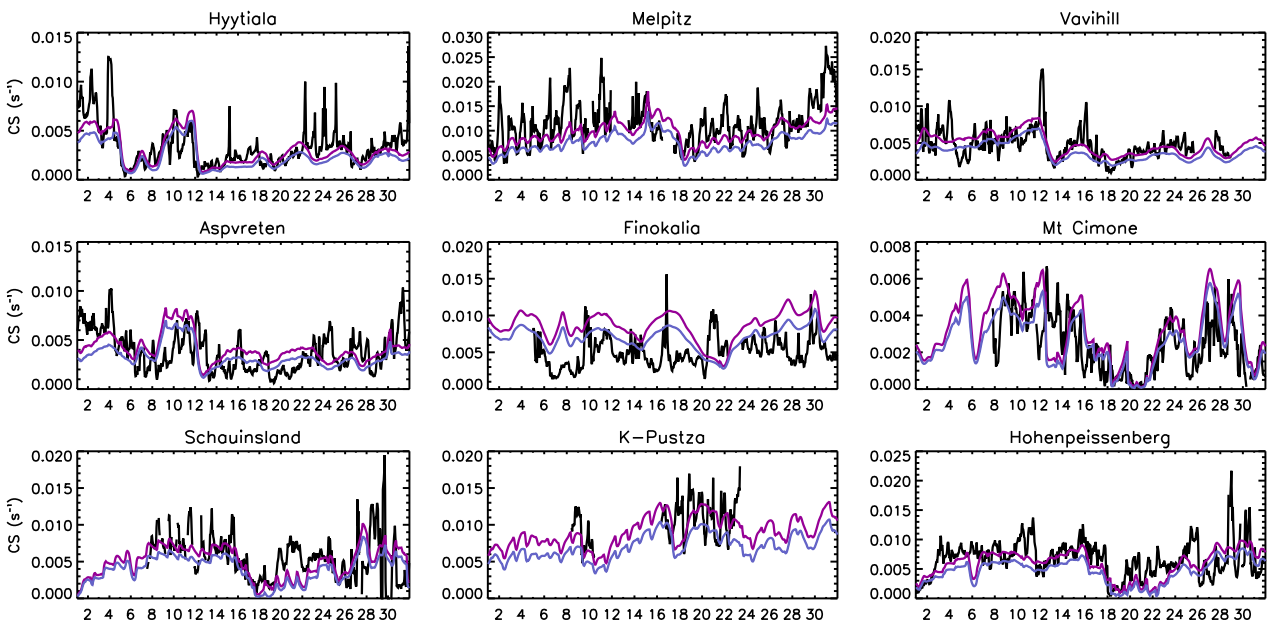

K-Pustzo

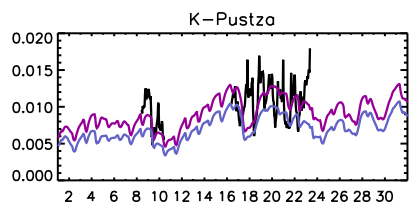

Hohenpeissenberg
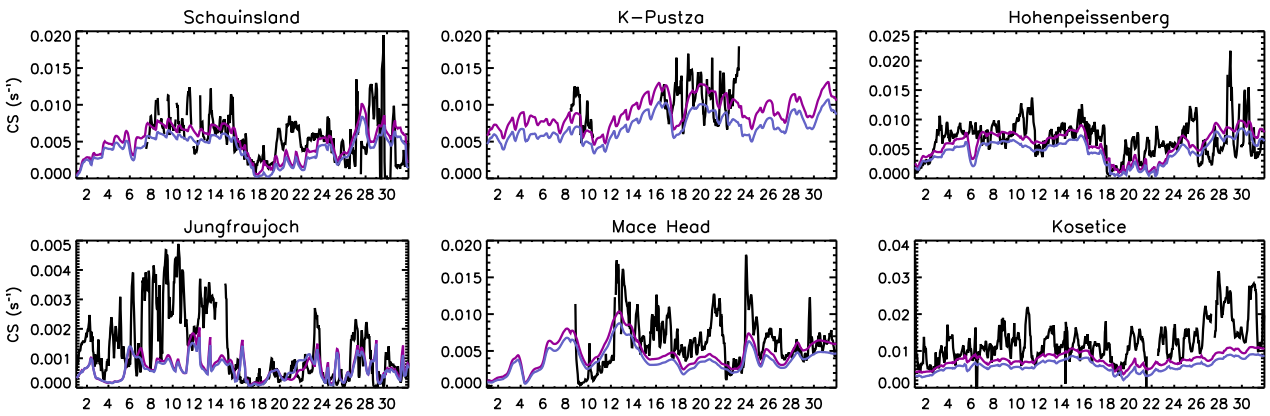

Mace Head

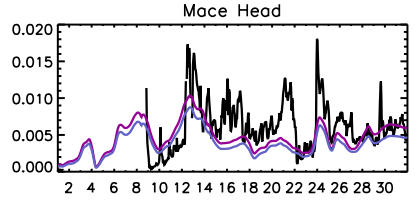

Cobouw
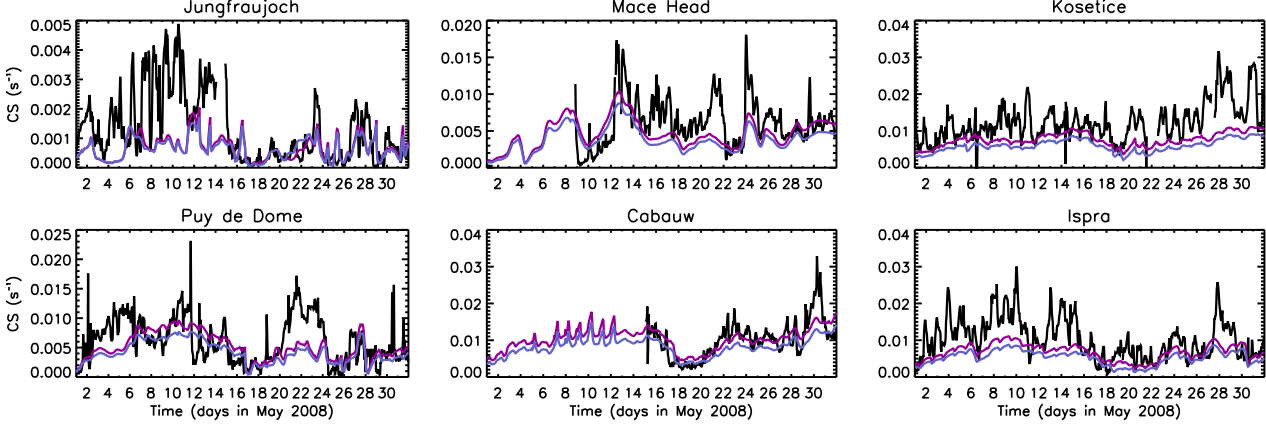

Ispro
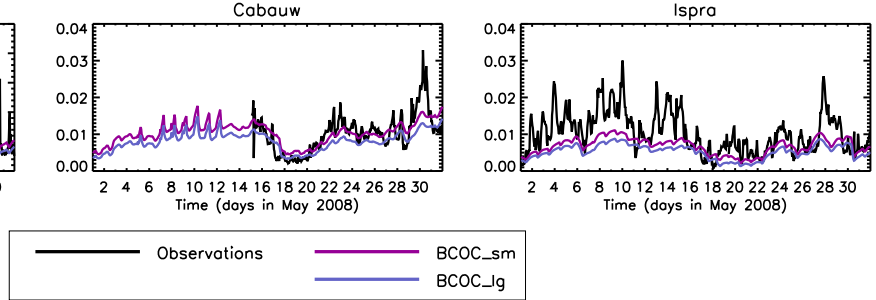

Fig. 12. May 2008 time-series of hourly-mean simulated (colour) and observed (black) condensation sink (CS) at each ground site. Model experiments, BCOC_lg and BCOC_sm, are described in Table 2.

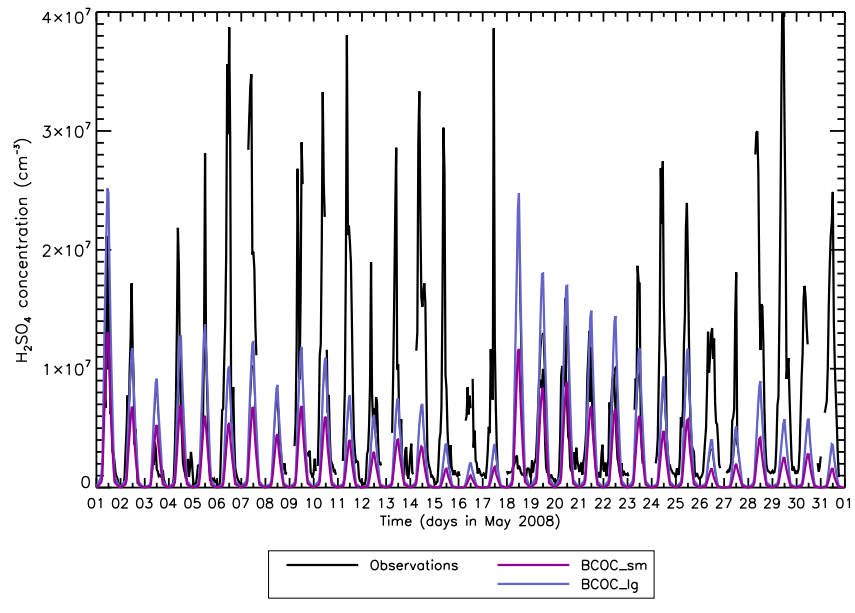

Fig. 13. Time-series of simulated (colour) and measured (black) concentrations of gas-phase sulphuric acid at the Melpitz ground site for May 2008. Model experiments, BCOC_lg and BCOC_sm, are described in Table 2. temporal resolution, additional nucleation mechanisms, and additional aerosol measurements such as the size distribution and non-volatile particles. This analysis was a demanding test for a global model, comparing with spatially and temporally intensive observations in a special meteorological situation over a relatively short period. During the campaign period, Central Europe was almost entirely influenced by easterly flow, which is not the most usual case.

We found that for the campaign period, the model was able to capture the mean particle number size distribution over Europe well for particle sizes relevant for CCN $\left(D_{\mathrm{p}}>50 \mathrm{~nm}\right)$ without the need for BL nucleation. The spatial distributions of campaign-mean number concentrations larger than $50 \mathrm{~nm}$ $\left(N_{50}\right)$ and $100 \mathrm{~nm}\left(N_{100}\right)$ dry diameter were well captured at the ground sites $\left(R^{2} \gtrsim 0.8\right)$. In addition, the normalised mean bias (NMB) between mean modelled and observed $N_{50}$ $(-18 \%)$ and $N_{100}(-1 \%)$ was small if we assumed a small size for emissions of $\mathrm{BC}+\mathrm{OC}$ particles, as used by AEROCOM (Dentener et al., 2006).

The mean number size distribution at sizes smaller than $50 \mathrm{~nm}$ diameter $\left(N_{<50}\right)$ was generally underpredicted in model experiments without BL nucleation. The difference 
between modelled and observed $N_{<50}$ was found to be statistically significant at all ground sites. The average overlap of modelled and observed frequency distributions of $N_{50}$ and $N_{100}$ was over $65 \%$ (with small primary BC+OC particles), but less than $55 \%$ for $N_{<50}$ without BL nucleation.

Comparisons with particle number concentrations roughly in the nucleation, Aitken, and accumulation mode size ranges measured by the DLR Falcon aircraft in the BL were consistent with the analysis of the ground station data. We found good agreement at the larger sizes but an increasing model underprediction of particle concentrations at the small end of the size distribution.

We tested four empirical parameterisations for secondary particle formation in the BL: the activation (ACT) and kinetic (KIN) mechanisms where the cluster formation rate is proportional to the gas-phase sulphuric acid concentration to the power 1 or 2 , respectively, and two newly developed mechanisms (ORG1 and ORG2) where the formation rate depends on the concentration low-volatility organic vapours in addition to sulphuric acid.

When BL nucleation was included in the model, the shape of the predicted campaign-mean size distribution at sizes $<50 \mathrm{~nm}$ was improved considerably, and the negative bias in $N_{<50}$ was reduced. The difference between modelled and observed $N_{<50}$ became statistically insignificant at roughly half of the ground sites with BL nucleation. The contribution of BL nucleation to $N_{50}$ and $N_{100}$ was difficult to detect within the uncertainty of the observations, but we found by including BL nucleation a small but significant difference was removed at 7 and 4 of the 15 sites for $N_{50}$ and $N_{100}$ respectively.

Despite the apparent model-observation agreement on a monthly-mean basis, our analysis showed that analysis of aggregated datasets (e.g. monthly-mean at individual sites or multi-site means) can be misleading. The model adequately captures the monthly-mean size distribution and the frequency distribution of particle concentrations, but on the hourly scale the model skill is poor. For example, the spatial correlation between monthly-mean $N_{\text {tot }}$ across all ground sites had an $R^{2}$ of 0.71 in the BCOC_sm model experiment, yet the hourly time series $R^{2}$ values were very low (average 0.08) and became lower still when BL nucleation was included (average 0.05).

The apparent model skill at capturing aggregated datasets, but poor performance at capturing temporal variability, needs to be taken into account in model evaluations. The poor temporal correlation between model and observations will be partly due to subgrid-scale stochastic processes such as changes in air mass, which the model is not able to capture due to its spatial resolution. However, there are deterministic processes important for particle number concentrations on an hourly scale that a global model is capable of capturing. For example, Spracklen et al. (2006) show good temporal agreement between GLOMAP and observations at the Hyytiälä surface site, which were driven by nucleation events and BL variability. To determine why the model is not as successful for this period would require more detailed analysis of the temporal variability at individual sites.

It is clear that for the conditions of May 2008 the model is unable to adequately capture the high variability observed in particle concentrations at the small end of the size distribution with all four BL nucleation mechanisms. Relatively good agreement between modelled and observed condensation sink at all sites suggested that the poor agreement was not due to the nucleation sink term, but more likely a result of an underprediction of sulphuric acid, which led to an underprediction of nucleation events during the first half of the IOP. The poor temporal agreement between modelled and observed $N_{\text {tot }}$ precludes any attempt to identify the best nucleation mechanism from such a short dataset.

The temporal correlation between model and observations increased with particle size, and the temporal pattern of $N_{100}$ (average 0.25 ) was in better agreement with the observations than of $N_{\text {tot. }}$. This suggests that concentrations of particles at sizes relevant for $\mathrm{CCN}$ are driven mainly by processes other than BL nucleation, which the model captures reasonably well. The relatively good agreement between modelled and observed hourly-mean and campaign-mean $N_{100}$ suggests that the contribution of BL nucleation needed to explain the observed $N_{100}$ is fairly small. However, the fingerprint of nucleation is hard to detect given the S/DMPS measurement uncertainty and the uncertainties in modelling of nucleation and precursor fields and in primary carbonaceous emissions. Thus, conclusions about the role of BL nucleation still have to be treated carefully.

There is large uncertainty associated with the prescribed size distribution of anthropogenic carbonaceous (BC and OC) particle emissions in regional and global aerosol models. The assumption of an initial size distribution for primary particles is necessary to account for both the size of particles at emission and sub-grid scale aerosol processes that influence the size and number concentrations of particles shortly after emission (Jacobson and Seinfeld, 2004; Pierce et al., 2009). However, information on the effective emission size distribution of carbonaceous aerosol for large-scale models is lacking in mass-based emission inventories (e.g. Cooke et al., 1999; Bond et al., 2004), and thus far has only been provided by AEROCOM (Dentener et al., 2006).

Based on our review of the literature, the mode diameter recommended by Dentener et al. (2006) for fossil fuel carbonaceous aerosol, appears to be smaller than that which is observed for directly emitted BC particles from traffic and urban emissions. In addition, taking into account sub-grid scale processing, the AEROCOM-recommended emission sizes may be too small to be appropriate for large model grid boxes. However, when we emit $\mathrm{BC}+\mathrm{OC}$ particles at small sizes (as recommended by AEROCOM; experiment BCOC_sm), the agreement with observed particle concentrations is generally much better than when we emit larger particles (experiment $\mathrm{BCOC}_{-} \mathrm{lg}$ ) that may be more realistic 
for low spatial resolution global models. Our analysis has not been able to resolve this issue.

The agreement between experiment $\mathrm{BCOC} \_$lg and the observations is generally improved when BL nucleation is included in the model. It is likely that the BCOC_sm experiment is compensating for missing particles from BL nucleation by increasing the primary particle number, and thus agrees better with observations. However, it is difficult to conclude whether or not BL nucleation would make up for the shortfall of experiment BCOC_lg since we do not adequately capture the observed nucleation events in this period. Even with high predicted nucleation-mode particle number concentrations with ORG1, BCOC_lg underpredicts $N_{50}$ at 13 out of 15 sites. Therefore, it is possible that the growth of nucleation mode particles may need to be increased to capture this part of the size distribution if we assume large $\mathrm{BC}+\mathrm{OC}$ particles.

The simplified SOA formation scheme used in the model, where a fixed fraction of the oxidised products of biogenic monoterpenes form SOA (neglecting contributions from anthropogenic volatile or intermediate-volatile organic compounds), may have large implications for the growth rate and survival of the particles formed by homogeneous nucleation. In addition, measurements of particle number concentrations at the surface and aloft may have been influenced by nitrate aerosol, particularly over NW Europe (Morgan et al., 2010), which the model does not account for. The role of nitrate and SOA from anthropogenic sources need to be evaluated in future modelling studies.

Comparisons with aircraft measurements of non-volatile particle number concentrations in the BL, suggest that the model is missing a fairly large fraction of non-volatile particles, particularly if a large emission size of primary $\mathrm{BC}+\mathrm{OC}$ particles is more appropriate for our model. Good agreement with the observations (NMB $=-3 \%$ ) was achieved only by decreasing the carbonaceous particle emission sizes to unrealistically small values (increasing the emitted number concentration by $\sim 70 \%$ relative to BCOC_sm and by more than a factor of 6 relative to BCOC_lg). Non-volatile residuals e.g. from mineral dust, sea spray, or BL nucleation that have not been included in the simulated non-volatile particle number concentration may partly explain the underprediction. With the simple representation of emitted carbonaceous particle number concentrations in the model we may also be missing non-volatile residuals from anthropogenic sources.

In a future study, we aim to improve the representation of the size and number concentration of anthropogenic primary particles in our model, by implementing a new European emission inventory from EUCAARI (Denier van der Gon et al., 2010). The emission inventory is based on emitted particle number concentration and size rather than aerosol mass. We will no longer need to assume a fixed lognormal size distribution for primary carbonaceous emissions, thus reducing the uncertainty associated with the initial size of $\mathrm{BC}+\mathrm{OC}$ particles appropriate for a global model. The parti- cle number emission inventory will also better represent the inhomogeneity of source size and how this influences the particle number size distribution in the BL.

It is important to note there are processes in addition to BL nucleation, condensational growth and primary particle emissions that influence the particle number size distribution over Europe, such as cloud processing, wet/dry deposition, coagulation, dynamics of semi-volatile size distributions etc. These processes have not been explored in detail in this study, but we are working towards a more complete uncertainty analysis of the GLOMAP aerosol model (Lee et al., 2011).

Acknowledgements. This research was supported by funding from the EU FP6 European Integrated Project on Aerosol Cloud Climate and Air Quality Interactions (EUCAARI) No. 036833-2 and the NERC ADIENT project. We acknowledge the European Super-sites for Atmospheric Aerosol Research (EUSAAR), German Ultrafine Aerosol Network (GUAN), and the Deutsches Zentrum für Luft- und Raumfahrt (DLR) for provision of data. The collection of number size distribution within GUAN was supported by the German Federal Ministry for the Environment, Nature Conservation and Nuclear (BMU) grant F\&E 370343200 (Title: "Erfassung der Zahl feiner und ultrafeiner Partikel in der Außenluft"). Special thanks to Thomas Elste and George Stange (DWD, Hohenpeissenberg) for $\mathrm{H}_{2} \mathrm{SO}_{4}$ measurements in Melpitz. The authors would also like to thank Amy J. Braverman, Senior Statistician at the California Institute of Technology, for guidance on statistical time series analysis.

Edited by: V.-M. Kerminen

\section{References}

Adams, P. J. and Seinfeld, J. H.: Predicting global aerosol size distributions in general circulation models, J. Geophys. Res., 107, 4370, doi:10.1029/2001JD001010, 2002.

Andres, R. J. and Kasgnoc, A. D.: A time-averaged inventory of subaerial volcanic sulfur emissions, J. Geophys. Res., 103, 25251, doi:10.1029/98JD02091, 1998.

Anttila, T., Vehkamäki, H., Napari, I., and Kulmala, M.: Effect of ammonium bisulphate formation on atmospheric water-sulphuric acid-ammonia nucleation, Boreal Environ. Res., 10, 511-523, 2005.

Arnold, S. R., Chipperfield, M. P., and Blitz, M. A.: A threedimensional model study of the effect of new temperaturedependent quantum yields for acetone photolysis, J. Geophys. Res., 110, D22305, doi:10.1029/2005JD005998, 2005.

Asmi, A., Wiedensohler, A., Laj, P., Fjaeraa, A.-M., Sellegri, K., Birmili, W., Weingartner, E., Baltensperger, U., Zdimal, V., Zikova, N., Putaud, J.-P., Marinoni, A., Tunved, P., Hansson, H.C., Fiebig, M., Kiveks, N., Lihavainen, H., Asmi, E., Ulevicius, V., Aalto, P. P., Swietlicki, E., Kristensson, A., Mihalopoulos, N., Kalivitis, N., Kalapov, I., Kiss, G., de Leeuw, G., Henzing, B., Harrison, R. M., Beddows, D., O’Dowd, C., Jennings, S. G., Flentje, H., Weinhold, K., Meinhardt, F., Ries, L., and 
Kulmala, M.: Number size distributions and seasonality of submicron particles in Europe 2008-2009, Atmos. Chem. Phys., 11, 5505-5538, doi:10.5194/acp-11-5505-2011, 2011.

Baltensperger, U., Streit, N., Weingartner, E., Nyeki, S., Prévôt, A. S. H., Van Dingenen, R., Virkkula, A., Putaud, J. P., Even, A., Ten Brink, H., Blatter, A., Neftel, A., and Gäggeler, H. W.: Urban and rural aerosol characterization of summer smog events during the PIPAPO field campaign in Milan, Italy, J. Geophys. Res., 107, 8193, doi:10.1029/2001JD001292, 2002.

Bauer, S. E., Menon, S., Koch, D., Bond, T. C., and Tsigaridis, K.: A global modeling study on carbonaceous aerosol microphysical characteristics and radiative effects, Atmos. Chem. Phys., 10, 7439-7456, doi:10.5194/acp-10-7439-2010, 2010.

Benkovitz, C. M., Trevor Scholtz, M., Pacyna, J., Tarrasón, L., Dignon, J., Voldner, E. C., Spiro, P. A., Logan, J. A., and Graedel, T. E.: Global gridded inventories of anthropogenic emissions of sulfur and nitrogen, J. Geophys. Res., 101, 2923929253, 1996.

Berresheim, H., Elste, T., Plass-Dülmer, C., Eiseleb, F. L., and Tannerb, D. J.: Chemical ionization mass spectrometer for long-term measurements of atmospheric $\mathrm{OH}$ and $\mathrm{H}_{2} \mathrm{SO}_{4}$, Int. J. Mass Spectrom., 202, 91-109, 2000.

Birmili, W., Weinhold, K., Nordmann, S., Weidensohler, A., Spindler, G., Müller, K., Herrmann, H., Gnauk, T., Pitz, M., Cyrya, J., Flentje, H., Nickel, C., Kuhlbusch, T. A. J., Loschau, G., Haase, D., Meinhardt, F., Schwerin, A., Ries, L., and Wirtz, K.: Atmospheric aerosol measurements in the German Ultrafine Aerosol Network (GUAN) part 1: soot and particle number size distributions, Gefahrst. Reinhalt. L., 69, 137-145, 2009.

Birmili, W., Heinke, K., Pitz, M., Matschullat, J., Wiedensohler, A., Cyrys, J., Wichmann, H.-E., and Peters, A.: Particle number size distributions in urban air before and after volatilisation, Atmos. Chem. Phys., 10, 4643-4660, doi:10.5194/acp-10-46432010, 2010.

Bond, T. C., Streets, D. G., Yarber, K. F., Nelson, S. M., Woo, J. H., and Klimont, Z.: A technology-based global inventory of black and organic carbon emissions from combustion, J. Geophys. Res., 109, D14203, doi:10.1029/2003JD003697, 2004.

Bond, T. C., Habib, G., and Bergstrom, R. W.: Limitations in the enhancement of visible light absorption due to mixing state, J. Geophys. Res., 111, D20211, doi:10.1029/2006JD007315, 2006.

Boy, M., Kazil, J., Lovejoy, E. R., Guenther, A., and Kulmala, M.: Relevance of ion-induced nucleation of sulfuric acid and water in the lower troposphere over the boreal forest at northern latitudes, Atmos. Res., 90, 151-158, 2008.

Burtscher, H., Baltensperger, U., Bukowiecki, N., Cohn, P., Hüglin, C., Mohr, M., Matter, U., Nyeki, S., Schmatloch, V., Streit, N., and Weingartner, E.: Separation of volatile and nonvolatile aerosol fractions by thermodesorption: instrumental development and applications, J. Aerosol Sci., 32, 427-442, 2001.

Casati, R., Scheer, V., Vogt, R., and Benter, T.: Measurements of nucleation and soot mode particle emission from a diesel passenger car in real world and laboratory in situ dilution, Atmos. Environ., 41, 2125-2135, 2007.

Chipperfield, M. P.: New version of the TOMCAT/SLIMCAT offline chemical transport model: Intercomparison of stratospheric tracer experiments, Q. J. Roy. Meteor. Soc., 132, 1179-1203, 2006.
Cofala, J., Amann, M., Klimont, Z., and Schopp, W.: Scenarios of World Anthropogenic Emissions of $\mathrm{SO}_{2}, \mathrm{NO}_{\mathrm{x}}$, and $\mathrm{CO}$ up to 2030, in: Internal report of the Transboundary Air Pollution Programme, p. 17, International Institute for Applied Systems Analysis, Laxenburg, Austria, 2005.

Cooke, W. F., Liousse, C., Cachier, H., and Feichter, J.: Construction of a $1 \times 1$ fossil fuel emission data set for carbonaceous aerosol and implementation and radiative impact in the ECHAM4 model, J. Geophys. Res., 104, 22137-22162, 1999.

Costabile, F., Birmili, W., Klose, S., Tuch, T., Wehner, B., Wiedensohler, A., Franck, U., König, K., and Sonntag, A.: Spatiotemporal variability and principal components of the particle number size distribution in an urban atmosphere, Atmos. Chem. Phys., 9, 3163-3195, doi:10.5194/acp-9-3163-2009, 2009.

Denier van der Gon, H., Visschedijk, A., Johansson, C., Ntziachristos, L., and Harrison, R.: Particle number inventory, Abstract 1E1, International Aerosol Conference 2010, Helsinki, Finland, 29 August-3 September, 2010.

Dentener, F., Kinne, S., Bond, T., Boucher, O., Cofala, J., Generoso, S., Ginoux, P., Gong, S., Hoelzemann, J. J., Ito, A., Marelli, L., Penner, J. E., Putaud, J.-P., Textor, C., Schulz, M., van der Werf, G. R., and Wilson, J.: Emissions of primary aerosol and precursor gases in the years 2000 and 1750 prescribed data-sets for AeroCom, Atmos. Chem. Phys., 6, 4321-4344, doi:10.5194/acp6-4321-2006, 2006.

Durbin, J. and Watson, G. S.: Testing for serial correlation in least squares regression: I, Biometrika, 37, 409-428, 1950.

Ehn, M., Petäjä, T., Birmili, W., Junninen, H., Aalto, P., and Kulmala, M.: Non-volatile residuals of newly formed atmospheric particles in the boreal forest, Atmos. Chem. Phys., 7, 677-684, doi:10.5194/acp-7-677-2007, 2007.

Elleman, R. A. and Covert, D. S.: Aerosol size distribution modeling with the Community Multiscale Air Quality modeling system in the Pacific Northwest: 2. Parameterizations for ternary nucleation and nucleation mode processes, J. Geophys. Res., 114, D11207, doi:10.1029/2009JD012187, 2009.

Engler, C., Rose, D., Wehner, B., Wiedensohler, A., Brüggemann, E., Gnauk, T., Spindler, G., Tuch, T., and Birmili, W.: Size distributions of non-volatile particle residuals $\left(D_{\mathrm{p}}<800 \mathrm{~nm}\right)$ at a rural site in Germany and relation to air mass origin, Atmos. Chem. Phys., 7, 5785-5802, doi:10.5194/acp-7-5785-2007, 2007.

Fuchs, N. A. and Sutugin, A. G.: High-dispersed aerosols, in: Topics in Current Aerosol Research, edited by: Hidy, G. M. and Brock, J. R., vol. 2, Pergamon Press, Oxford, 1-60, 1971.

Geller, M. D., Sardar, S. B., Phuleria, H., Philip, M., and Sioutas, C.: Measurements of particle number and mass concentrations and size distributions in a tunnel environment, Environ. Sci. Technol., 39, 8653-8663, 2005.

Gilardoni, S., Vignati, E., and Wilson, J.: Using measurements for evaluation of black carbon modeling, Atmos. Chem. Phys., 11, 439-455, doi:10.5194/acp-11-439-2011, 2011.

Gong, S. L., Barrie, L. A., Blanchet, J. P., Von Salzen, K., Lohmann, U., Lesins, G., Spacek, L., Zhang, L. M., Girard, E., Lin, H., Leaitch, R., Leighton, H., Chylek, P., and Huang, P.: Canadian Aerosol Module: a size-segregated simulation of atmospheric aerosol processes for climate and air quality models 1. Module development, J. Geophys. Res., 108, 4007, doi:10.1029/2001JD002002, 2003.

Guenther, A., Hewitt, C. N., Erickson, D., Fall, R., Geron, C., 
Graedel, T., Harley, P., Klinger, L., Lerdau, M., McKay, W. A., Pierce, T., Scholes, B., Steinbrecher, R., Tallamraju, R., Taylor, J., and Zimmerman, P.: A global model of natural volatile organic compound emissions, J. Geophys. Res., 100, 8873-8892, 1995.

Hamburger, T., McMeeking, G., Minikin, A., Birmili, W., Dall'Osto, M., O’Dowd, C., Flentje, H., Henzing, B., Junninen, H., Kristensson, A., de Leeuw, G., Stohl, A., Burkhart, J. F., Coe, H., Krejci, R., and Petzold, A.: Overview of the synoptic and pollution situation over Europe during the EUCAARILONGREX field campaign, Atmos. Chem. Phys., 11, 10651082, doi:10.5194/acp-11-1065-2011, 2011.

Harris, S. J. and Maricq, M. M.: Signature size distributions for diesel and gasoline engine exhaust particulate matter, J. Aerosol Sci., 32, 749-764, 2001.

Henne, S., Brunner, D., Folini, D., Solberg, S., Klausen, J., and Buchmann, B.: Assessment of parameters describing representativeness of air quality in-situ measurement sites, Atmos. Chem. Phys., 10, 3561-3581, doi:10.5194/acp-10-3561-2010, 2010.

Henze, D. K., Seinfeld, J. H., Ng, N. L., Kroll, J. H., Fu, T.-M., Jacob, D. J., and Heald, C. L.: Global modeling of secondary organic aerosol formation from aromatic hydrocarbons: highvs. low-yield pathways, Atmos. Chem. Phys., 8, 2405-2420, doi:10.5194/acp-8-2405-2008, 2008.

Holtslag, A. A. M. and Boville, B. A.: Local versus nonlocal boundary-layer diffusion in a global climate model, J. Climate, 6, 1825-1842, 1993.

Jacobson, M. Z. and Seinfeld, J. H.: Evolution of nanoparticle size and mixing state near the point of emission, Atmos. Environ., 38, 1839-1850, 2004.

Jennings, S. G. and O'Dowd, C. D.: Volatility of aerosol at Mace Head, on the west coast of Ireland, J. Geophys. Res., 95, 13937, doi:10.1029/JD095iD09p13937, 1990.

Abdul-Khalek, I. S., Kittelson, D. B., and Brear, F.: Nanoparticle Growth During Dilution and Cooling of Diesel Exhaust: Experimental Investigation and Theoretical Assessment, SAE Technical Paper 2000-01-1515, 2000.

Kerminen, V.-M. and Kulmala, M.: Analytical formulae connecting the "real" and the "apparent" nucleation rate and the nuclei number concentration for atmospheric nucleation events, J. Aerosol Sci., 33, 609-622, doi:10.1016/S0021-8502(01)00194-X, 2002.

Kerminen, V.-M., Lihavainen, H., Komppula, M., Viisanen, Y., and Kulmala, M.: Direct observational evidence linking atmospheric aerosol formation and cloud droplet activation, Geophys. Res. Lett., 32, L14803, doi:10.1029/2005GL023130, 2005.

Kerminen, V.-M., Petäjä, T., Manninen, H. E., Paasonen, P., Nieminen, T., Sipilä, M., Junninen, H., Ehn, M., Gagné, S., Laakso, L., Riipinen, I., Vehkamäki, H., Kurten, T., Ortega, I. K., Dal Maso, M., Brus, D., Hyvärinen, A., Lihavainen, H., Leppä, J., Lehtinen, K. E. J., Mirme, A., Mirme, S., Hõrrak, U., Berndt, T., Stratmann, F., Birmili, W., Wiedensohler, A., Metzger, A., Dommen, J., Baltensperger, U., Kiendler-Scharr, A., Mentel, T. F., Wildt, J., Winkler, P. M., Wagner, P. E., Petzold, A., Minikin, A., Plass-Dülmer, C., Pöschl, U., Laaksonen, A., and Kulmala, M.: Atmospheric nucleation: highlights of the EUCAARI project and future directions, Atmos. Chem. Phys., 10, 10829-10848, doi:10.5194/acp-10-10829-2010, 2010.

Kettle, A. J. and Andreae, M. O.: Flux of dimethylsulfide from the oceans: a comparison of updated data sets and flux models, J.
Geophys. Res., 105, 26793-26808, 2000.

Kittelson, D. B.: Engines and nanoparticles: a review, J. Aerosol Sci., 29, 575-588, 1998.

Kittelson, D. B., Johnson, J., Watts, W., Wei, Q., Drayton, M., Paulsen, D., and Bukowiecki, N.: Diesel aerosol sampling in the atmosphere, Society of Automotive Engineers, Technical Paper Series, No. 2000-01-2212, doi:10.4271/2000-01-2212, 2000.

Kittelson, D. B., Watts, W. F., and Johnson, J. P.: On-road and laboratory evaluation of combustion aerosols - Part1: Summary of diesel engine results, J. Aerosol Sci., 37, 913-930, 2006.

Kuang, C., McMurry, P. H., and McCormick, A. V., Determination of cloud condensation nuclei production from measured new particle formation events, Geophys. Res. Lett., 36, L09822, doi:10.1029/2009GL037584, 2009.

Kulmala, M. and Laaksonen, A.: Binary nucleation of watersulfuric acid system: comparison of classical theories with different $\mathrm{H}_{2} \mathrm{SO}_{4}$ saturation vapor pressures, J. Chem. Phys., 93, 696701, 1990.

Kulmala, M., Laaksonen, A., and Pirjola, L.: Parameterizations for sulfuric acid/water nucleation rates, J. Geophys. Res., 103, 83018307, 1998.

Kulmala, M., Pirjola, L., and Mäkelä, J. M.: Stable sulphate clusters as a source of new atmospheric particles, Nature, 404, 66-69, 2000.

Kulmala, M., Dal Maso, M., Mäkelä, J. M., Pirjola, L., Väkevä, M., Aalto, P., Miikkulainen, P., Hämeri, K., and O'Dowd, C. D.: On the formation, growth and composition of nucleation mode particles, Tellus B, 53, 479-490, doi:10.1034/j.16000889.2001.530411.x, 2001.

Kulmala, M., Vehkamäki, H., Petäjä, T., Dal Maso, M., Lauri, A., Kerminen, V.-M., Birmili, W., and McMurry, P. H.: Formation and growth rates of ultrafine atmospheric particles: a review of observations, J. Aerosol Sci., 35, 143-176, 2004.

Kulmala, M., Lehtinen, K. E. J., and Laaksonen, A.: Cluster activation theory as an explanation of the linear dependence between formation rate of $3 \mathrm{~nm}$ particles and sulphuric acid concentration, Atmos. Chem. Phys., 6, 787-793, doi:10.5194/acp-6-787-2006, 2006.

Kulmala, M., Riipinen, I., Sipilä, M., Manninen, H. E., Petäjä, T., Junninen, H., Maso, M. D., Mordas, G., Mirme, A., Vana, M., Hirsikko, A., Laakso, L., Harrison, R. M., Hanson, I., Leung, C., Lehtinen, K. E. J., and Kerminen, V.-M.: Toward direct measurement of atmospheric nucleation, Science, 318, 89-92, doi:10.1126/science.1144124, 2007.

Kulmala, M., Asmi, A., Lappalainen, H. K., Carslaw, K. S., Pöschl, U., Baltensperger, U., Hov, Ø., Brenquier, J.-L., Pandis, S. N., Facchini, M. C., Hansson, H.-C., Wiedensohler, A., and O'Dowd, C. D.: Introduction: European Integrated Project on Aerosol Cloud Climate and Air Quality interactions (EUCAARI) integrating aerosol research from nano to global scales, Atmos. Chem. Phys., 9, 2825-2841, doi:10.5194/acp-9-2825-2009, 2009.

Laakso, L., Mäkelä, J. M., Pirjola, L., and Kulmala, M.: Model studies on ion-induced nucleation in the atmosphere, J. Geophys. Res., 107, 4427, doi:10.1029/2002JD002140, 2002.

Laakso, L., Gagné, S., Petäjä, T., Hirsikko, A., Aalto, P. P., Kulmala, M., and Kerminen, V.-M.: Detecting charging state of ultra-fine particles: instrumental development and ambient measurements, Atmos. Chem. Phys., 7, 1333-1345, doi:10.5194/acp-7-1333- 
2007, 2007.

Laaksonen, A., Hamed, A., Joutsensaari, J., Hiltunen, L., Cavalli, F., Junkermann, W., Asmi, A., Fuzzi, S., and Facchini, M. C.: Cloud condensation nucleus production from nucleation events at a highly polluted region, Geophys. Res. Lett., 32, L06812, doi:10.1029/2004GL022092, 2005.

Lee, L. A., Carslaw, K. S., Pringle, K., Mann, G. W., and Spracklen, D. V.: Emulation of a complex global aerosol model to quantify sensitivity to uncertain parameters, Atmos. Chem. Phys. Discuss., 11, 20433-20485, doi:10.5194/acpd-11-20433-2011, 2011.

Lihavainen, H., Kerminen, V.-M., Komppula, M., Hatakka, J., Aaltonen, V., Kulmala, M., and Viisanen, Y.: Production of "potential" cloud condensation nuclei associated with atmospheric newparticle formation in northern Finland, J. Geophys. Res., 108, 4782, doi:10.1029/2003JD003887, 2003.

Liu, P. S. K., Leaitch, W. R., Strapp, J. W., and Wasey, M. A.: Response of particle measuring systems airborne ASASP and PCASP to $\mathrm{NaCl}$ and latex particles, Aerosol Sci. Tech., 16, 8395, 1992.

Lohmann, U. and Feichter, J.: Global indirect aerosol effects: a review, Atmos. Chem. Phys., 5, 715-737, doi:10.5194/acp-5-7152005, 2005.

Lucas, D. D. and Akimoto, H.: Evaluating aerosol nucleation parameterizations in a global atmospheric model, Geophys. Res. Lett., 33, L10808, doi:10.1029/2006GL025672, 2006.

McMurry, P. and Friedlander, S.: New particle formation in the presence of an aerosol, Atmos. Environ., 13, 1635-1651, 1979.

Merikanto, J., Napari, I., Vehkamäki, H., Anttila, T., and Kulmala, M.: New parameterization of sulfuric acid-ammonia-water ternary nucleation rates at tropospheric conditions, J. Geophys. Res., 112, D15207, doi:10.1029/2006JD007977, 2007.

Merikanto, J., Spracklen, D. V., Mann, G. W., Pickering, S. J., and Carslaw, K. S.: Impact of nucleation on global CCN, Atmos. Chem. Phys., 9, 8601-8616, doi:10.5194/acp-9-8601-2009, 2009.

Metzger, A., Verheggen, B., Dommen, J., Duplissy, J., Prevot, A. S. H., Weingartner, E., Riipinen, I., Kulmala, M., Spracklen, D. V., Carslaw, K. S., and Baltensperger, U.: Evidence for the role of organics in aerosol particle formation under atmospheric conditions, P. Natl. Acad. Sci. USA, 107, 66466651, doi:10.1073/pnas.0911330107, 2010.

Modgil, M. S., Kumar, S., Tripathi, S. N., and Lovejoy, E. R.: A parameterization of ion-induced nucleation of sulphuric acid and water for atmospheric conditions, J. Geophys. Res., 110, D19205, doi:10.1029/2004JD005475, 2005.

Morgan, W. T., Allan, J. D., Bower, K. N., Esselborn, M., Harris, B., Henzing, J. S., Highwood, E. J., Kiendler-Scharr, A., McMeeking, G. R., Mensah, A. A., Northway, M. J., Osborne, S., Williams, P. I., Krejci, R., and Coe, H.: Enhancement of the aerosol direct radiative effect by semi-volatile aerosol components: airborne measurements in North-Western Europe, Atmos. Chem. Phys., 10, 8151-8171, doi:10.5194/acp-10-8151-2010, 2010.

Nightingale, P. D., Liss, P. S., and Schlosser, P.: Measurements of air-sea gas transfer during an open ocean algal bloom, Geophys. Res. Lett., 27, 2117-2120, 2000.

O'Dowd, C. D. and Smith, M. H.: Physicochemical properties of aerosols over the Northeast Atlantic: evidence for wind-speed- related submicron sea-salt aerosol production, J. Geophys. Res., 98, 1137-1149, 1993.

Paasonen, P., Sihto, S.-L., Nieminen, T., Vuollekoski, H., Riipinen, I., Plaß-Dülmer, C., Berresheim, H., Birmili, W., and Kulmala, M.: Connection between new particle formation and sulphuric acid at Hohenpeissenberg (Germany) including the influence of organic compounds, Boreal Environ. Res., 14, 616-629, 2009.

Paasonen, P., Nieminen, T., Asmi, E., Manninen, H. E., Petäjä, T., Plass-Dülmer, C., Flentje, H., Birmili, W., Wiedensohler, A., Hõrrak, U., Metzger, A., Hamed, A., Laaksonen, A., Facchini, M. C., Kerminen, V.-M., and Kulmala, M.: On the roles of sulphuric acid and low-volatility organic vapours in the initial steps of atmospheric new particle formation, Atmos. Chem. Phys., 10, 11223-11242, doi:10.5194/acp-10-11223-2010, 2010.

Pierce, J. R. and Adams, P. J.: Efficiency of cloud condensation nuclei formation from ultrafine particles, Atmos. Chem. Phys., 7, 1367-1379, doi:10.5194/acp-7-1367-2007, 2007.

Pierce, J. R. and Adams, P. J.: Uncertainty in global CCN concentrations from uncertain aerosol nucleation and primary emission rates, Atmos. Chem. Phys., 9, 1339-1356, doi:10.5194/acp-91339-2009, 2009.

Pierce, J. R., Theodoritsi, G., Adams, P. J., and Pandis, S. N.: Parameterization of the effect of sub-grid scale aerosol dynamics on aerosol number emission rates, J. Aerosol Sci., 40, 385-393, 2009.

Putaud, J. P., Raes, F., Van Dingenen, R., Brüggemann, E., Facchini, M. C., Decesari, S., Fuzzi, S., Gehrig, R., Hüglin, C., Laj, P., Lorbeer, G., Maenhaut, W., Mihalopoulos, N., Muller, K., Querol, X., Rodriguez, S., Schneider, J., Spindler, G., tenBrink, H., Torseth, K., and Wiedensohler, A.: A European aerosol phenomenology - 2: chemical characteristics of particulate matter at kerbside, urban, rural and background sites in Europe, Atmos. Environ., 38, 2579-2595, 2004.

Ramanathan, V., Crutzen, P. J., Kiehl, J. T., and Rosenfeld, D.: Aerosols, climate, and the hydrological cycle, Science, 294, 2119-2124, doi:10.1126/science.1064034, 2001.

Riipinen, I., Sihto, S.-L., Kulmala, M., Arnold, F., Dal Maso, M., Birmili, W., Saarnio, K., Teinil, K., Kerminen, V.-M., Laaksonen, A., and Lehtinen, K. E. J.: Connections between atmospheric sulphuric acid and new particle formation during QUEST III-IV campaigns in Heidelberg and Hyytiälä, Atmos. Chem. Phys., 7, 1899-1914, doi:10.5194/acp-7-1899-2007, 2007.

Roldin, P., Swietlicki, E., Massling, A., Kristensson, A., Löndahl, J., Eriksson, A., Pagels, J., and Gustafsson, S.: Aerosol ageing in an urban plume - implication for climate, Atmos. Chem. Phys., 11, 5897-5915, doi:10.5194/acp-11-5897-2011, 2011.

Robinson, A. L., Donahue, N. M., Shrivastava, M. K., Weitkamp, E. A., Sage, A. M., Grieshop, A. P., Lane, T. E., Pierce, J. R., and Pandis, S. N.: Rethinking organic aerosols: Semivolatile emissions and photochemical ageing, Science, 315, 1259-1262, 2007.

Rose, D., Wehner, B., Ketzel, M., Engler, C., Voigtländer, J., Tuch, T., and Wiedensohler, A.: Atmospheric number size distributions of soot particles and estimation of emission factors, Atmos. Chem. Phys., 6, 1021-1031, doi:10.5194/acp-6-1021-2006, 2006.

Sgro, L. A., Borghese, A., Speranza, L., Barone, A. C., Minutolo, P., Bruno, A., Danna, A., and DAlessio, A.: Measurements of 
nanoparticles of organic carbon and soot in flames and vehicle exhausts, Environ. Sci. Technol., 42, 859-863, 2008.

Sihto, S.-L., Kulmala, M., Kerminen, V.-M., Dal Maso, M., Petäjä, T., Riipinen, I., Korhonen, H., Arnold, F., Janson, R., Boy, M., Laaksonen, A., and Lehtinen, K. E. J.: Atmospheric sulphuric acid and aerosol formation: implications from atmospheric measurements for nucleation and early growth mechanisms, Atmos. Chem. Phys., 6, 4079-4091, doi:10.5194/acp-6-4079-2006, 2006.

Sipilä, M., Berndt, T., Petäjä, T., Brus, D., Vanhanen, J., Stratmann, F., Patokoski, J., Mauldin, R. L., Hyvärinen, A.P., Lihavainen, H., and Kulmala, M.: The role of sulfuric acid in atmospheric nucleation, Science, 327, 1243-1246, doi:10.1126/science.1180315, 2010.

Spracklen, D. V., Pringle, K. J., Carslaw, K. S., Chipperfield, M. P., and Mann, G. W.: A global off-line model of sizeresolved aerosol microphysics: I. Model development and prediction of aerosol properties, Atmos. Chem. Phys., 5, 22272252, doi:10.5194/acp-5-2227-2005, 2005a.

Spracklen, D. V., Pringle, K. J., Carslaw, K. S., Chipperfield, M. P., and Mann, G. W.: A global off-line model of size-resolved aerosol microphysics: II. Identification of key uncertainties, Atmos. Chem. Phys., 5, 3233-3250, doi:10.5194/acp-5-3233-2005, $2005 b$.

Spracklen, D. V., Carslaw, K. S., Kulmala, M., Kerminen, V.-M., Mann, G. W., and Sihto, S.-L.: The contribution of boundary layer nucleation events to total particle concentrations on regional and global scales, Atmos. Chem. Phys., 6, 5631-5648, doi:10.5194/acp-6-5631-2006, 2006.

Spracklen, D. V., Carslaw, K. S., Kulmala, M., Kerminen, V.-M., Sihto, S.-L., Riipinen, I., Merikanto, J., Mann, G. W., Chipperfield, M. P., Wiedensohler, A., Birmili, W., and Lihavainen, H.: Contribution of particle formation to global cloud condensation nuclei concentrations, Geophys. Res. Lett., 35, L06808, doi:10.1029/2007GL033038, 2008.

Spracklen, D. V., Carslaw, K. S., Merikanto, J., Mann, G. W., Reddington, C. L., Pickering, S., Ogren, J. A., Andrews, E., Baltensperger, U., Weingartner, E., Boy, M., Kulmala, M., Laakso, L., Lihavainen, H., Kivekäs, N., Komppula, M., Mihalopoulos, N., Kouvarakis, G., Jennings, S. G., O’Dowd, C., Birmili, W., Wiedensohler, A., Weller, R., Gras, J., Laj, P., Sellegri, K., Bonn, B., Krejci, R., Laaksonen, A., Hamed, A., Minikin, A., Harrison, R. M., Talbot, R., and Sun, J.: Explaining global surface aerosol number concentrations in terms of primary emissions and particle formation, Atmos. Chem. Phys., 10, 4775-4793, doi:10.5194/acp-10-4775-2010, 2010.

Spracklen, D. V., Carslaw, K. S., Pöschl, U., Rap, A., and Forster, P. M.: Global cloud condensation nuclei influenced by carbonaceous combustion aerosol, Atmos. Chem. Phys., 11, 9067-9087, doi:10.5194/acp-11-9067-2011, 2011.

Stier, P., Feichter, J., Kinne, S., Kloster, S., Vignati, E., Wilson, J., Ganzeveld, L., Tegen, I., Werner, M., Balkanski, Y., Schulz, M., Boucher, O., Minikin, A., and Petzold, A.: The aerosolclimate model ECHAM5-HAM, Atmos. Chem. Phys., 5, 11251156, doi:10.5194/acp-5-1125-2005, 2005.

Textor, C., Schulz, M., Guibert, S., Kinne, S., Balkanski, Y., Bauer, S., Berntsen, T., Berglen, T., Boucher, O., Chin, M., Dentener, F., Diehl, T., Easter, R., Feichter, H., Fillmore, D., Ghan, S., Ginoux, P., Gong, S., Grini, A., Hendricks, J., Horowitz, L., Huang,
P., Isaksen, I., Iversen, I., Kloster, S., Koch, D., Kirkevåg, A., Kristjansson, J. E., Krol, M., Lauer, A., Lamarque, J. F., Liu, X., Montanaro, V., Myhre, G., Penner, J., Pitari, G., Reddy, S., Seland, Ø., Stier, P., Takemura, T., and Tie, X.: Analysis and quantification of the diversities of aerosol life cycles within AeroCom, Atmos. Chem. Phys., 6, 1777-1813, doi:10.5194/acp-61777-2006, 2006.

Van Dingenen, R., Raes, F., Putaud, J.-P., Baltensperger, U., Charron, A., Facchini, M. C., Decesari, S., Fuzzi, S., Gehrig, R., Hansson, H.-C., Harrison, R. M., Hüglin, C., Jones, A. M., Laj, P., Lorbeer, G., Maenhaut, W., Palmgren, F., Querol, X., Rodriguez, S., Schneider, J., ten Brink, H., Tunved, P., Tørseth, K., Wehner, B., Weingartner, E., Wiedensohler, A., and Wåhlin, P.: A European aerosol phenomenology - 1: physical characteristics of particulate matter at kerbside, urban, rural and background sites in Europe, Atmos. Environ., 38, 2561-2577, 2004.

Vehkamäki, H., Kulmala, M., Napari, I., Lehtinen, K. E. J., Timmreck, C., Noppel, M., and Laaksonen, A.: An improved parameterization for sulfuric acid-water nucleation rates for tropospheric and stratospheric conditions, J. Geophys. Res., 107, 4622, doi:10.1029/2002JD002184, 2002.

Venzac, H., Sellegri, K., Villani, P., Picard, D., and Laj, P.: Seasonal variation of aerosol size distributions in the free troposphere and residual layer at the puy de Dme station, France, Atmos. Chem. Phys., 9, 1465-1478, doi:10.5194/acp-9-1465-2009, 2009.

Wang, S. C. and Flagan, R. C.: Scanning electrical mobility spectrometer, Aerosol Sci. Tech., 13, 230-240, 1990.

Wang, M. and Penner, J. E.: Aerosol indirect forcing in a global model with particle nucleation, Atmos. Chem. Phys., 9, 239-260, doi:10.5194/acp-9-239-2009, 2009.

Weber, R. J., Marti, J. J., McMurry, P. H., Eisele, F. L., Tanner, D. J., and Jefferson, A.: Measured atmospheric new particle formation rates: implications for nucleation mechanisms, Chem. Eng. Commun., 151, 53-64, 1996.

Wehner, B., Birmili, W., Gnauk, T., and Wiedensohler, A.: Particle number size distributions in a street canyon and their transformation into the urban-air background: measurements and a simple model study, Atmos. Environ., 36, 2215-2223, 2002.

Wehner, B., Philippin, S., Wiedensohler, A., Scheer, V., Vogt, R.: Variability of non-volatile fractions of atmospheric aerosol particles with traffic influence, Atmos. Environ., 38, 6081-6090, 2004.

Wehner, B., Petäjä, T., Boy, M., Engler, C., Birmili, W., Tuch, T., Wiedensohler, A., and Kulmala, M.: The contribution of sulfuric acid and non-volatile compounds on the growth of freshly formed atmospheric aerosols, Geophys. Res. Lett., 32, L17810, doi:10.1029/2005GL023827, 2005.

Wehner, B., Uhrner, U., von Löwis, S., Zallinger, M., and Wiedensohler, A.: Aerosol number size distributions within the exhaust plume of a diesel and a gasoline passenger car under on-road conditions and determination of emission factors, Atmos. Environ., 43, 1235-1245, 2009.

Weimer, S., Mohr, C., Richter, R., Keller, J., Mohr, M., Prevot, A.S.H., and Baltensperger, U.: Mobile measurements of aerosol number and volume size distributions in an Alpine valley: Influence of traffic versus wood burning, Atmos. Environ., 43, 624 630, 2009.

Weingartner, E., Nyeki, S., and Baltensperger, U.: Seasonal and diurnal variation of aerosol size distributions $(10<D<750 \mathrm{~nm})$ at 
a high-alpine site (Jungfraujoch $3580 \mathrm{~m}$ a.s.1.), J. Geophys. Res., 104, 26809, doi:10.1029/1999JD900170, 1999.

Wiedensohler, A., Birmili, W., Nowak, A., Sonntag, A., Weinhold, K., Merkel, M., Wehner, B., Tuch, T., Pfeifer, S., Fiebig, M., Fjäraa, A. M., Asmi, E., Sellegri, K., Depuy, R., Venzac, H., Villani, P., Laj, P., Aalto, P., Ogren, J. A., Swietlicki, E., Roldin, P., Williams, P., Quincey, P., Hglin, C., Fierz-Schmidhauser, R., Gysel, M., Weingartner, E., Riccobono, F., Santos, S., Grüning, C., Faloon, K., Beddows, D., Harrison, R. M., Monahan, C., Jennings, S. G., O’Dowd, C. D., Marinoni, A., Horn, H.-G., Keck, L., Jiang, J., Scheckman, J., McMurry, P. H., Deng, Z., Zhao, C. S., Moerman, M., Henzing, B., and de Leeuw, G.: Particle mobility size spectrometers: harmonization of technical standards and data structure to facilitate high quality long-term observations of atmospheric particle number size distributions, Atmos. Meas. Tech. Discuss., 3, 5521-5587, doi:10.5194/amtd-3-55212010, 2010.

van der Werf, G. R., Randerson, J. T., Collatz, G. J., and Giglio, L.: Carbon emissions from fires in tropical and subtropical ecosystems, Glob. Change Biol., 9, 547-562, 2003.

Wilks, D. S.: Resampling hypothesis tests for autocorrelated fields, J. Climate, 10, 66-82, 1997.

Yu, F. and Luo, G.: Simulation of particle size distribution with a global aerosol model: contribution of nucleation to aerosol and CCN number concentrations, Atmos. Chem. Phys., 9, 76917710, doi:10.5194/acp-9-7691-2009, 2009.
Yu, F., Luo, G., Bates, T. S., Anderson, B., Clarke, A., Kapustin, V., Yantosca, R. M., Wang, Y., and Wu, S.: Spatial distributions of particle number concentrations in the global troposphere: simulations, observations, and implications for nucleation mechanisms, J. Geophys. Res., 115, D17205, doi:10.1029/2009JD013473, 2010.

Zhang, K. M. and Wexler, A. S.: Evolution of particle number distribution near roadways Part I: analysis of aerosol dynamics and its implications for engine emission measurement. Atmos. Environ., 38, 6643-6653, 2004.

Zhang, K. M., Wexler, A. S., Zhu, Y. F., Hinds, W. C., and Sioutas, C.: Evolution of particle number distributions near roadways Part II: the road-to-ambient process, Atmos. Environ., 38, 66556665, 2004.

Zhang, K. M., Wexler, A. S., Niemeier, D. A., Yi, F. Z., Hinds, W. C., and Sioutas, C.: Evolution of particle number distribution near roadways. Part III: Traffic analysis and on-road size resolved particulate emission factors, Atmos. Environ., 39, 4155-4166, 2005.

Zhu, Y., Hinds, W.C., Kim, S., Shen, S., and Sioutas, C.: Study of ultrafine particles near a major highway with heavy-duty diesel traffic, Atmos. Environ. 36, 4323-4335, 2002. 